\title{
A comprehensive review of sucker rod pumps' components, diagnostics, mathematical models, and common failures and mitigations
}

\author{
Sherif Fakher $^{1}$ (D) Abdelaziz Khlaifat $^{1} \cdot$ M. Enamul Hossain ${ }^{1} \cdot$ Hashim Nameer $^{1,2}$
}

Received: 12 June 2021 / Accepted: 18 August 2021 / Published online: 27 August 2021

(c) The Author(s) 2021

\begin{abstract}
In many oil reservoirs worldwide, the downhole pressure does not have the ability to lift the produced fluids to the surface. In order to produce these fluids, pumps are used to artificially lift the fluids; this method is referred to as artificial lift. More than seventy percent of all currently producing oil wells are being produced by artificial lift methods. One of the most applied artificial lift methods is sucker rod pump. Sucker rod pumps are considered a well-established technology in the oil and gas industry and thus are easy to apply, very common worldwide, and low in capital and operational costs. Many advancements in technology have been applied to improve sucker rod pumps performance, applicability range, and diagnostics. With these advancements, it is important to be able to constantly provide an updated review and guide to the utilization of the sucker rod pumps. This research provides an updated comprehensive review of sucker rod pumps components, diagnostics methods, mathematical models, and common failures experienced in the field and how to prevent and mitigate these failures. Based on the review conducted, a new classification of all the methods that can fall under the sucker rod pump technology based on newly introduced sucker rod pump methods in the industry has been introduced. Several field cases studies from wells worldwide are also discussed in this research to highlight some of the main features of sucker rod pumps. Finally, the advantages and limitations of sucker rod pumps are mentioned based on the updated review. The findings of this study can help increase the understanding of the different sucker rod pumps and provide a holistic view of the beam rod pump and its properties and modeling.
\end{abstract}

Sucker Rod Pumps · Comprehensive Review · Sucker Rod Failures and Mitigations · Suker Rod Diagnostics

$\begin{array}{ll}\begin{array}{ll}\text { Abbreviations } \\ a^{2}\end{array} & \text { Velocity force propagation } \\ v & \text { Damping factor } \\ u(x, t) & \text { Displacement of the sucker rod at arbitrary } \\ & \text { depth and time } \\ L & \text { Length of the sucker rod string } \\ \text { PPRL } & \text { Peak polished rod load } \\ \text { MPRL } & \text { Minimum polished rod load } \\ W_{f} & \text { Weight of the fluid column } \\ W_{r} & \text { Weight of the rods in air } \\ A & \text { Area } \\ C_{D} & \text { Viscous damping coefficient } \\ A_{r} & \text { Cross-sectional area of the rod }\end{array}$

Sherif Fakher

sherif.fakher@aucegypt.edu

1 Petroleum and Energy Engineering, The American University in Cairo, Cairo, Egypt

2 Baiti, Iraq
$A$ and $B \quad$ Constants empirically derived

$S_{F} \quad$ Represents environmental effects; Service Factor

$S_{a} \quad$ Fatigue endurance limit

$S_{\text {min }} \quad$ Minimum rod stress

$T \quad$ Minimum tensile strength of the rod material

$A_{i} \quad$ Metal area of the rod in the $i$ th taper

$a_{i}-d_{i} \quad$ Are best fitting line parameters

$L_{i} \quad$ Sucker rod length

$P_{\text {inflow }} \quad$ Inflow pressure

$P_{\text {outflow }} \quad$ Outflow pressure

$P_{\text {wh }} \quad$ Wellhead pressure

E $\quad$ Young's modulus

$g \quad$ Gravitational constant

$t \quad$ Time

$u \quad$ Elongation

$\rho \quad$ Density

$N \quad$ Matrix that represents the wave equation

I Unit matrix, also known as the filter matrix

- 
W Newly obtained set of data with the least global error

$f_{r} \quad$ Fluid velocity

$F_{\text {rf }} \quad$ Viscous force per unit length of rod

$F_{\text {cf }} \quad$ Viscous force per rod coupling per unit length of rod

$F_{\mathrm{rt}} \quad$ Friction force between tubing and rod per unit length of rod

$F_{C, \text { API }} \quad$ Equals unity for a uniform rod taper

$U, G, H$ Column vectors defined based on initial and boundary conditions

\section{Introduction}

Sucker rod pumps include a wide range of artificial lift methods (Diaz et al. 2009; Guo et al. 2003; Mo and Xu 2000; Spears 1989; Arambulo et al. 2020). With the advancement in technology, the types of artificial lift methods that fall under the sucker rod classification have increased (Gauchel 1985; Yi et al. 2019; Byrd and Hale 1970; Pino et al. 2020; Nickell 2020; Shakhmatov 2020). These methods are used to increase oil recovery from relatively low-rate wells that are producing moderate to heavy crude oils with a moderate level of gas and solid particles (McCaslin 1988; Jacobs 1986; Jackson et al. 2003). Sucker rod pumps are used widely in the industry due to their multiple advantages including relatively low cost, well established technology, availability, and wide applicability range (Martin 2012; Teodoriu and Pienknagura 2018; Takacs 1997; Takacs and Mihaly 2017; Takacs and Gajda 2014).

Several researchers have attempted to model the sucker rod pump using different methods. McCafferty (1993) illustrated the importance of calculating the maximum available compression ratio compared to the required compression ratio for sucker rod installation designs. Jennings (1989) showed some of the most important parameters that are needed for a proper design of the sucker rod pump. These parameters included reservoir rock and fluid properties, wellbore properties, and operational properties. Peng et al. (2019) used a deep autoencoder neural network to obtain features of the dynamometer card which can minimize information loss and improve data management. Langbauer and Antretter (2017) used finite element method for improvement of the sucker rod pump efficiency by increasing production and reducing cost and failure. Using finite element method managed to improve sucker rod performance by $30 \%$. Ferrigno et al. (2018) compared the results of the dynamometer cards obtained from controllers and telemetry with other software that consider friction effects in deviated wells. Chen et al. (2018) used the Fourier series method to solve sucker rod prediction problems using the conventional surface dynamometer card. Caicedo and Carma (2009) introduced another sucker rod analysis method other than the conventional dynamometer card. This method introduces and algorithm to generate piston tubing rod performance curve. Chevelcha et al. (2013) performed tests on the sucker rod pump in an attempt to obtain a relation between the noise produced by a well during sucker rod operation and its relation to the sucker rod condition.

Experimental and field analysis of sucker rod pumps have also been conducted to evaluate the importance of some factors on sucker rod performance and failure. Podio et al. (2003) presented results for tests with a sucker rod pump model in the laboratory to provide information on dynamic and static pump friction measurement. They reasoned that one of the major costs during production is the lifting cost. It should be optimized by minimizing down time, and increasing the pump efficiency through loss reduction. $\mathrm{Xu}$ and $\mathrm{Hu}$ (1993) showed that using the assumption that the sucker rod for deviated wells can be performed using the conventional vertical wells models can lead to serious errors. Dave and Mustafa (2017) presented a comparison between the different sucker rod artificial lift systems based on the production area, depth, downhole failures, power saving, and safety concerns. Allison et al. (2018) studied the impact of gas on sucker rod pumps and found that they have the advantages of tolerating gas production without damage to the pump itself, however the overall volumetric efficiency of the pump is reduced significantly due to gas presence, up to $40 \%$. Ali et al. (2015) performed a screening criterion for sucker rod pumps and compared their performance to that of electrical submersible pumps. Gauchel (1985) presented the results for a test design for fiber glass sucker rods to determine tensile, shear, and tensile/tensile fatigue performance as a function of temperature. Reynolds (1988) performed a review on the advantages of fiberglass sucker rods compared to steel sucker rods.

Many researchers have studied the sucker rod pump and attempted to improve its design and applicability. Very few have attempted to combine this knowledge together in order to provide a holistic review on the most current advancements in the sucker rod pump. Also, since new sucker rod designs are being added under the sucker rod classification, a new comprehensive classification of what types of artificial lift pumps can fall under the naming of the sucker rod pump is needed. This research addresses these gaps by performing a comprehensive review of the main type of sucker rod pumps, the beam rod pump, components, diagnostics methods, mathematical models, and common failures experienced in the field and how to prevent and mitigate these failures. The research also provides a new classification of all methods that can fall under the sucker rod pump technology based on newly introduced sucker rod pump methods in the industry. The main focus of this review is the beam rod 
pumping unit since it is the main type of sucker rod pumps and is also the most widely used worldwide.

The research begins by introducing a new classification of sucker rod pumps based on the novel pump designs that have been recently introduced in the industry. Following this, the main focus of the research is on the beam rod pump, which is the most widely used sucker rod pump. The components of the beam rod pump are explained in detail, along with the diagnostics methods used to evaluate the performance of the beam rod pump. The most widely applied mathematical models used with the beam rod pump are then mentioned and explained. This is followed by a detailed failure analysis of the beam rod pump based on field studies. For all the failure mechanisms, a mitigation recommendation is also provided based on the comprehensive literature review. Advancements in the beam rod system are then mentioned and the added value of each advancement is explained. Finally, beam rod pump case studies worldwide are mentioned along with their results and the beneficial information gained from each case study. Using all the data collected, the advantages and limitations of the beam rod pump are then mentioned. Figure 1 shows a flowchart for the research conducted and the problems studied.

\section{Sucker rod pump classification}

Sucker rod pumps include a wide range of methods used to increase oil recovery. Since classifications have varied significantly along the years mainly due to the development of new technologies, the first step in this research is to include a new classification of sucker rod pumps that includes all the new technological developments that fall under this category.

\section{Beam rod pumping}

The beam rod pumping unit is the most applied sucker rod method (Jalikop et al. 2020), shown in Fig. 2. This method will also be the main focus of this research. It is mainly composed of a surface unit and downhole pump and rods. The surface unit has multiple variations based on the size

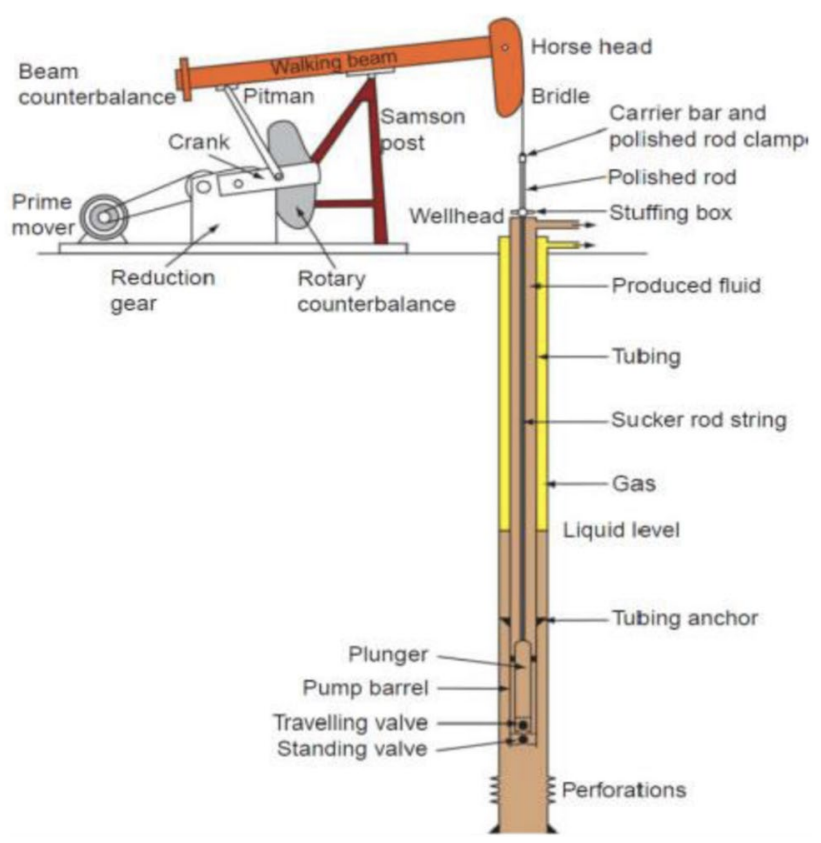

Fig. 2 Beam rod pump (Wang et al. 2018)

Fig. 1 Research flowchart

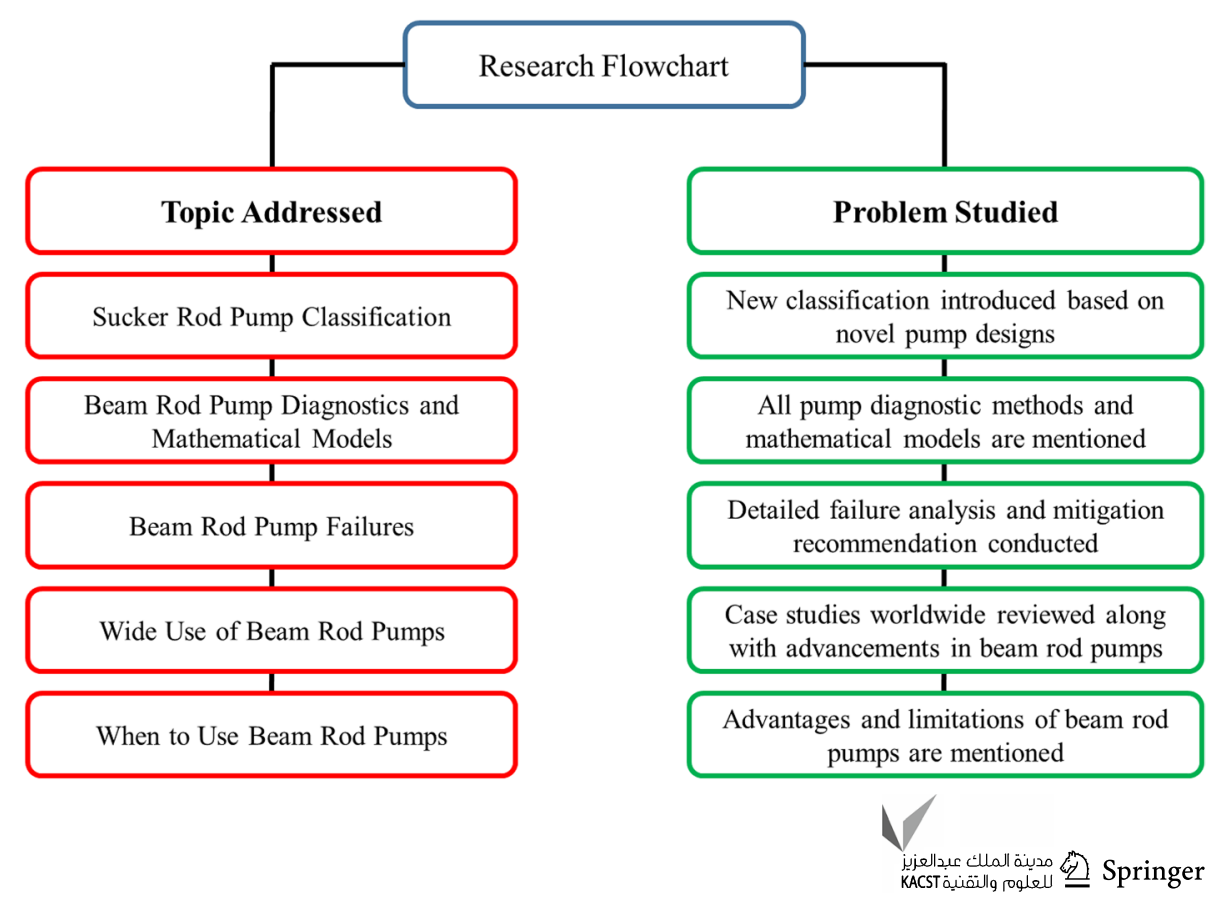


and application. The three main types are the Type $A, C$, and $M$ beam rod. Type $A$ (Air balanced) uses compressed air to counterbalance the load that comes from the rods. Type $A$ has the benefit of reduced weight and lower installation and transportation cost. Type $M$ (Mark II) lowers the torque and power requirements throughout the pumping cycle. Type $C$ is the conventional beam rod pump; a detailed description of this type will be provided in this review (Teodoriu and Pienknagura 2018).

\section{Coiled tubing sucker rod}

The use of coiled tubing as sucker rods is mainly performed in small diameter holes. This technology was first applied in Argentina and was then used in the USA and Canada (Parekh and Desai 2013). It has the advantage of reducing cost since the coiled tubing acts as both the production string and the sucker rod. This method also reduces time during well intervention jobs and allows the conduction of various operations in live wells without the need of kill fluid. An example of coiled tubing sucker rod is presented in Fig. 3. Some of key design parameters in this type of sucker rod pump are the coiled tubing material, fatigue failure analysis, corrosion resistance, completion design, non-return valve (one way valve), gas separation, and surface facilities (Parekh and Desai 2013).

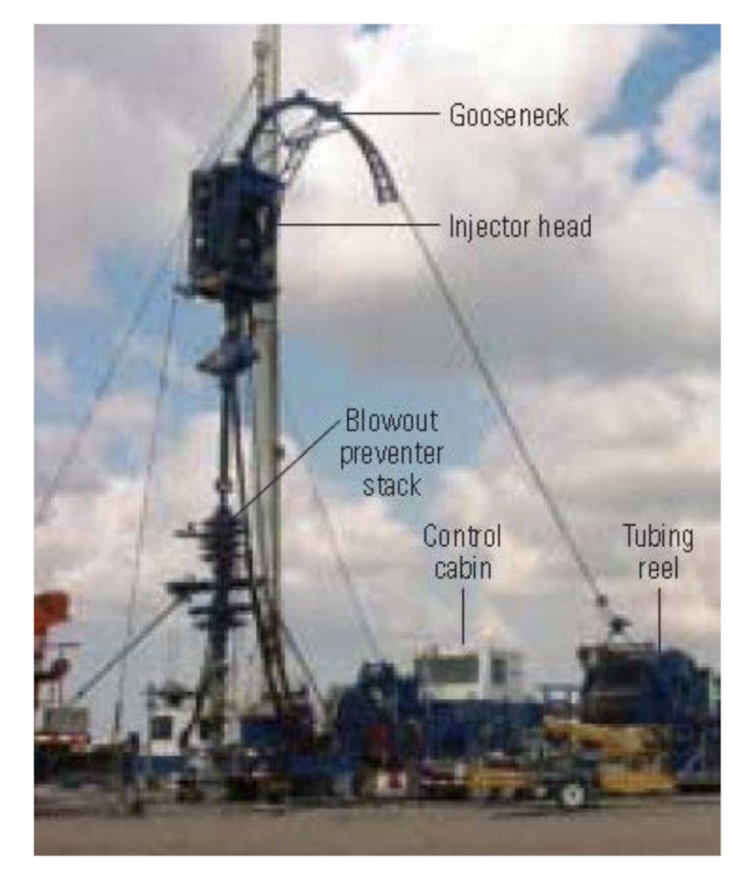

Fig. 3 Coiled tubing sucker rod (Parekh and Desai 2013)

\section{Hydraulically actuated sucker rods}

Hydraulically actuated sucker rods have been present since the 1940s. They contain a hydraulic cylinder at the surface used to impart a reciprocating motion on the polished rod and the rod string, and the downhole assembly which is almost identical to the conventional beam unit (Phillips et al. 2013). Figure 4 presents an illustration of the surface components of the hydraulically actuated sucker rod pump.

The hydraulically actuated sucker rod pump has the following advantages (Phillips et al. 2013):

- Is not subject to damaging torque limitations.

- Has no structural loading concerns.

- Polished rod velocity is linear for the majority of the stroke

- Can operate at depths up to $14,000 \mathrm{ft}$

- Can operate in high rate wells with thousands of bpd

- Can operate in shallow wells.

- Better paraffin, solids, and gas handling

- Has dual well capabilities

The two main limitations of the hydraulically actuated sucker rod pump include high maintenance cost and frequent failures compared to the conventional beam pumping unit.

\section{Linear rod pumping}

Linear rod pumping has the advantage of removing the bulky surface components of the conventional beam pumping unit.

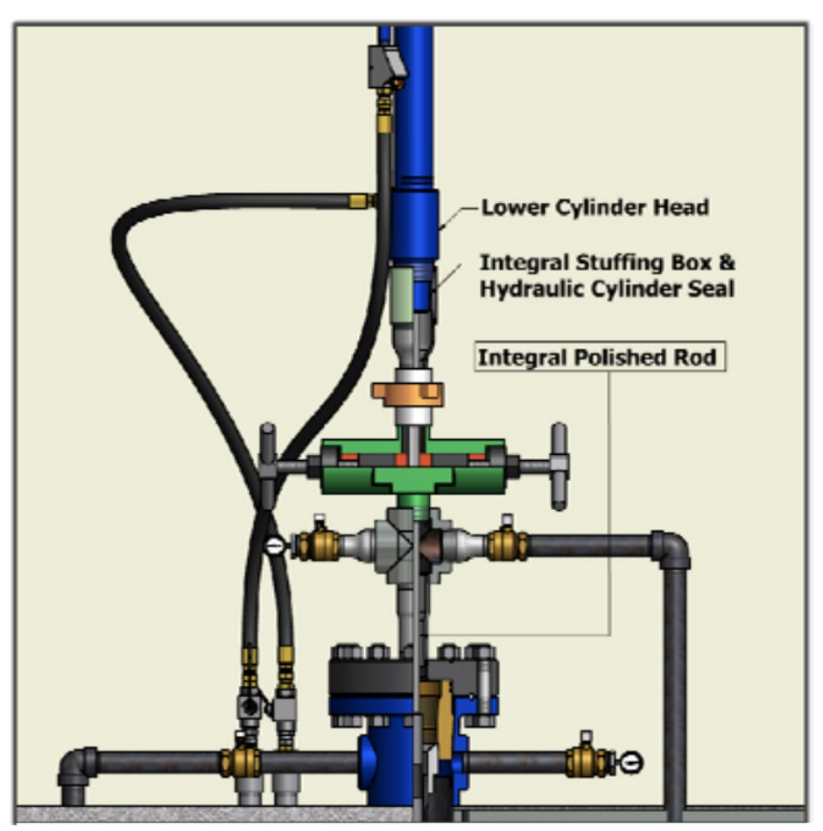

Fig. 4 Hydraulically actuated sucker rods (Phillips et al. 2013) 
This increases the applicability of the sucker rod artificial lift method by allowing it to be used when the surface space is limited where size is important, most notably in offshore applications. The downhole components are very similar to those of the conventional beam pumping unit (Khadav et al. 2016; Lima and Neto 2020). An illustration of the linear rod pumping unit surface components is presented in Fig. 5.

\section{Long stroke sucker rod}

The long stroke sucker rod is one of the least utilized sucker rod methods. It could be considered a variation of the linear rod pumping. It is designed to increase the stroke length of the sucker rod string in order to increase applicability of sucker rod pumps in deeper wells with higher capacity and reduction in fatigue (Dave et al. 2017; Teodoriu and Pienknagura 2018). An image of the surface components of the long stroke sucker rod is shown in Fig. 6.

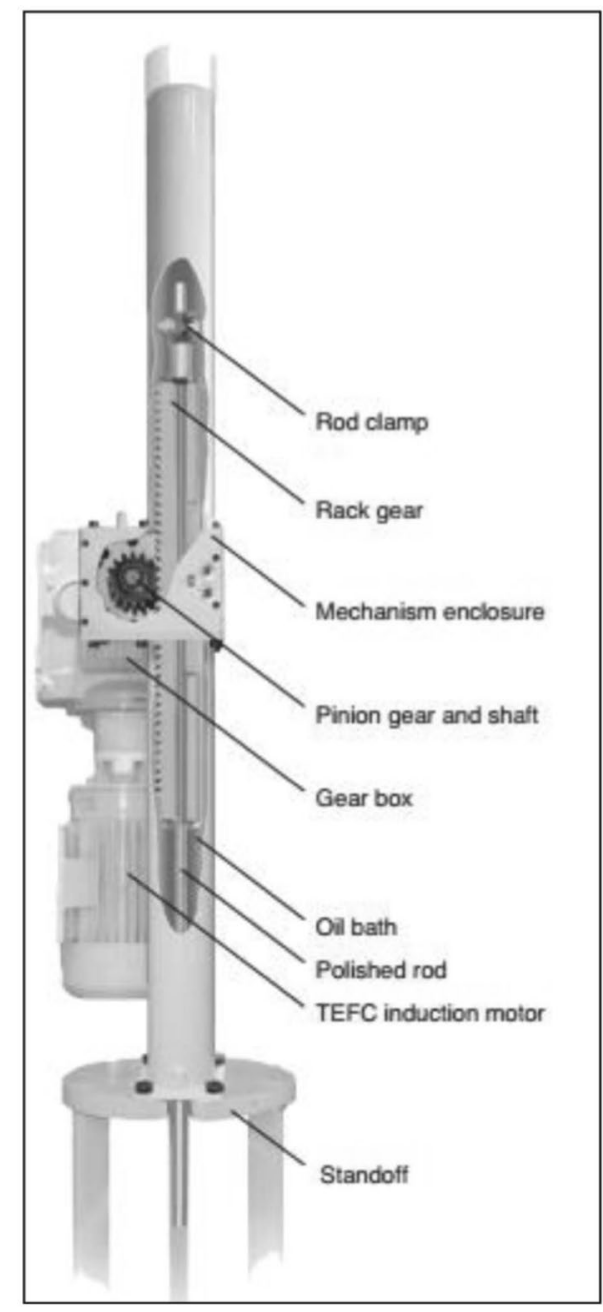

Fig. 5 Linear rod pumping (Khadav et al. 2016)

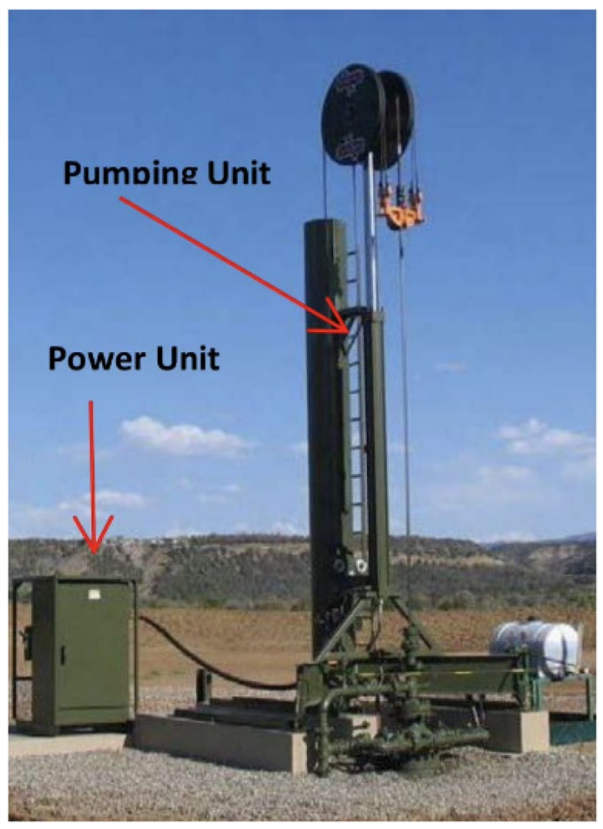

Fig. 6 Long stroke sucker rod (Dave et al. 2017)

\section{Adjustable counterbalance sucker rod pump}

Oliva et al. (2020) developed an adjustable counterbalance sucker rod pumping unit that they referred to as "smart sucker rod pump" which can adjust the counterbalance and the polished rod stroke length without the needed for personnel to go to the field. The adjustable counterbalance sucker rod system has the advantage of being able to adjust the polished rod stroke range easily, and the counterweight can also be adjusted at any position inside the adaptable grid. A comparison between the conventional beam pumping unit and the adjustable counterbalance sucker rod pump is shown in Fig. 7.

\section{Beam rod pump components}

The conventional beam rod pumping unit consists of surface components and downhole components. These components all function together to allow for the production of the hydrocarbons from the wellbore to the surface (Di et al. 2018). The main components of the beam pumping unit, shown in Fig. 8, are as follows:

- Prime Mover The prime mover converts the energy provided through electricity or a diesel engine into motion that is transmitted to the gear box.

- Gear Box The gear box is the main mechanism by which the surface component motion is controlled. 

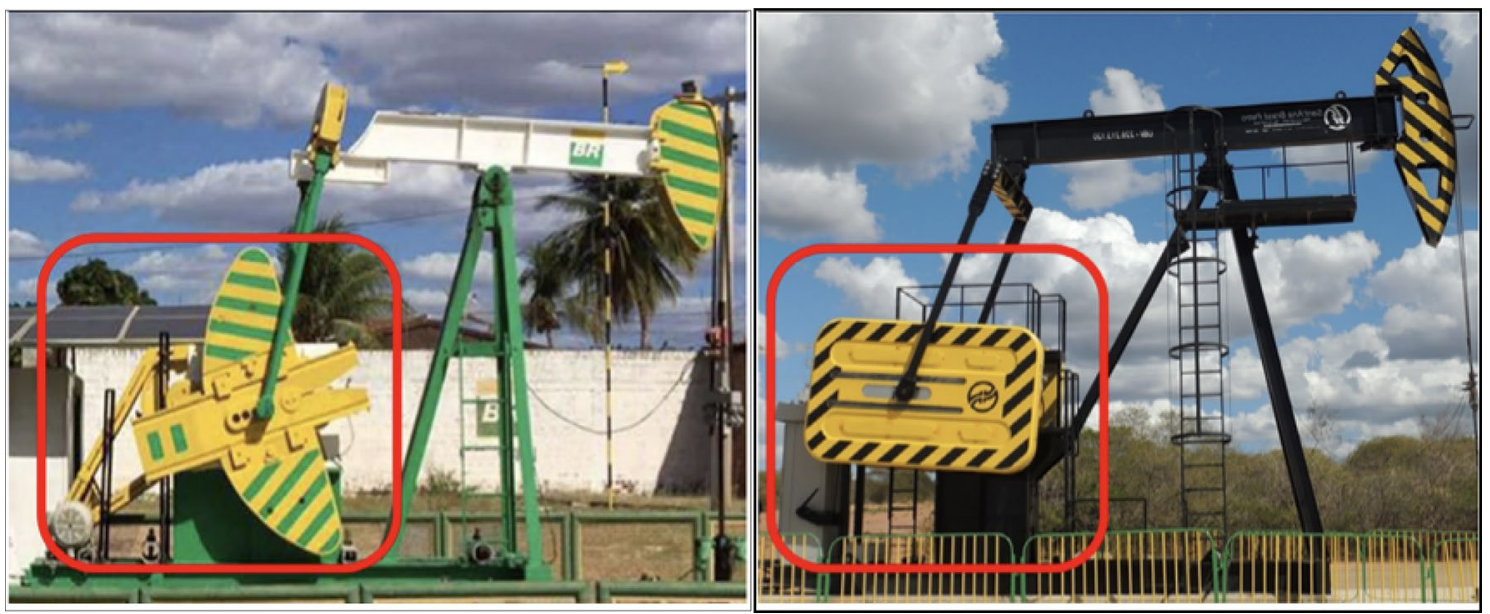

Fig. 7 Conventional and smart sucker rod pump (Oliva et al. 2020)

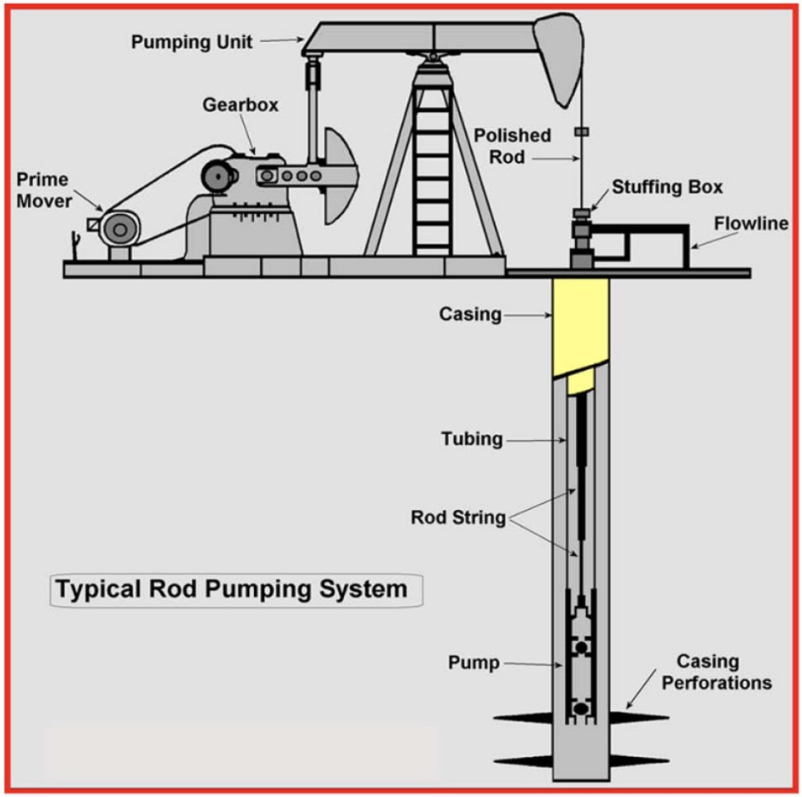

Fig. 8 Beam rod pump main components (Di et al. 2018)

- Counterbalance The counterbalance works to balance the weight of the horse head as it moves up and down to allow for smooth and regulated operation and to reduce wear of the surface components.

- Horse Head (Pumping Unit) The horse hear is the surface pumping unit that move up and down to allow the downhole pump components to operate. It carries the weight of the string.

- Polished Rod The polished rod is the topmost sucker rod. It is usually designed from more durable material compared to the other sucker rods since it is carrying the entire weight of the string.
- Stuffing Box Its main function is to prevent leakage of fluid by providing a seal between the components.

- Tubing The tubing is the piping through which the fluid is produced after it travels through the sucker rods.

- Rod String (Sucker Rods) The sucker rods make up the main length of the string. They are specially shaped in order to accommodate the fluids and work with the overall design.

- Downhole Pump The downhole pump is composed of several components mainly the traveling valve and the standing valves. During the upstroke, the traveling valve closes and the fluid above the plunger is lifted. This allows the barrel to fill up with fluid through the standing valve. During the downstroke, the standing valve closes and the fluid is compressed thus allowing the fluid to move through the traveling valve.

- Flowline The produced fluids flow into the flowline in the surface in order to be transported to the refinery.

\section{Beam rod pump diagnostic methods}

The main method by which beam rod pumps diagnostics is conducted is the dynamometer card. Other methods have also arisen to overcome some of the drawbacks of the dynamometer card. These methods include either updates or modifications of the conventional dynamometer card, or other methods not related to the dynamometer card. All of these methods, starting with the dynamometer card, are explained in this section.

\section{Dynamometer card}

Dynamometer is comprised of the word dynamo meaning power or force and meter which is a unit of length 


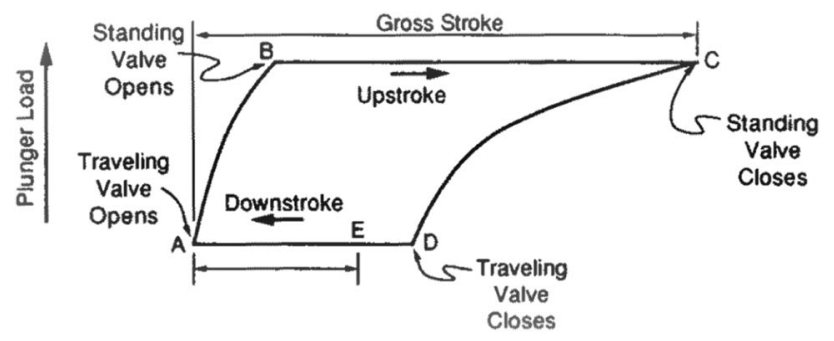

Fig. 9 Dynamometer card example (Peng 2019)

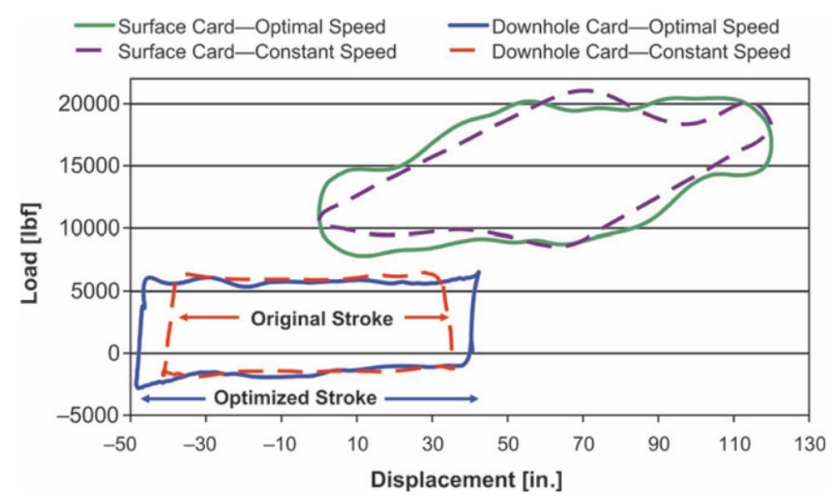

Fig. 10 Surface and downhole dynamometer cards examples (Palka and Czyz 2009)

measurement. Therefore, the dynamometer card is a measurement of the load of the entire cycle of the sucker rod pump as a function of the position at which the force is measured. The dynamometer card is a plot of the load and displacement at each time step during a stroke as a function of the plunger load (Palka and Czyz 2009; Tommaso and Marfella 2018; Peng et al. 2019; Ferrigno et al. 2018; Chen et al. 2018). An example of a conventional dynamometer card is shown in Fig. 9. The load on both the traveling valve and the standing valve can be determined as a function of position.

When generated, there are usually two dynamometer cards including the surface and the downhole. The surface card is plotted relative to the surface readings, whereas the downhole dynamometer card is plotted relative to downhole conditions. Figure 10 shows the difference between both. Most of the operators rely on the downhole card due to its higher accuracy in depicting real case conditions. The main drawbacks in the downhole card however are data delay, noise inaccuracy, and inaccurate readings (Palka and Czyz 2009).

Based on the readings of the downhole and surface dynamometer cards, several conventional charts have been found to be very similar regardless of the reservoir and wellbore being studied. A summary of these dynamometer charts and their equivalent description is shown in Table 1.

\section{Other methods}

Although the dynamometer card is the main method used for bucker rod diagnostics, it has some drawbacks which led to the rise of other methods for beam rod pump diagnostics. These methods include modification to the dynamometer card, and other methods not reliant on the dynamometer card. A description of these methods is provided in Table 2.

\section{Beam rod pump mathematical models}

Modeling of the behavior and properties of the beam rod pump can be done using different equations. The main equation used to model beam rod pump is the wave equation. Since this equation is a partial differential equation, several solutions to this model have arisen based on the initial and boundary conditions and assumptions used to solve the wave equation. Other mathematical equations not reliant on the wave equation also exist. The main mathematical equations used to model the beam rod pump behavior and properties are summarized in Table 3. The equation, terminology description, and usage are mentioned for each model.

\section{Beam rod pump common failures and mitigation}

The main failures of the beam rod pump can be categorized into three main segments including mechanical, operational, and electrical failures. With each segment, several factors can contribute to the failure of the beam rod pump. The main failure mechanisms for the beam rod pump are summarized in Fig. 11. A detailed description of each segment and its sub-categories will be explained.

\section{Mechanical failures}

The main mechanical failures discussed in this research that occur with the beam pumping unit include tubing failure, friction, rod wear, pin and coupling wear, surface component failure, and pump failure.

\section{Tubing failure and friction}

During production, the downhole string of the sucker rod may sometimes collide with the tubing string. This friction may result in erosion and wear of both the tubing and the sucker rods. This could eventually lead to severe leakages and breakage of both components. Figure 12 shows an

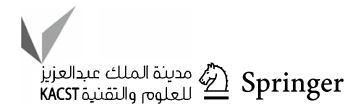


Table 1 Dynamometer card common shapes and description (Wang et al. 2021)

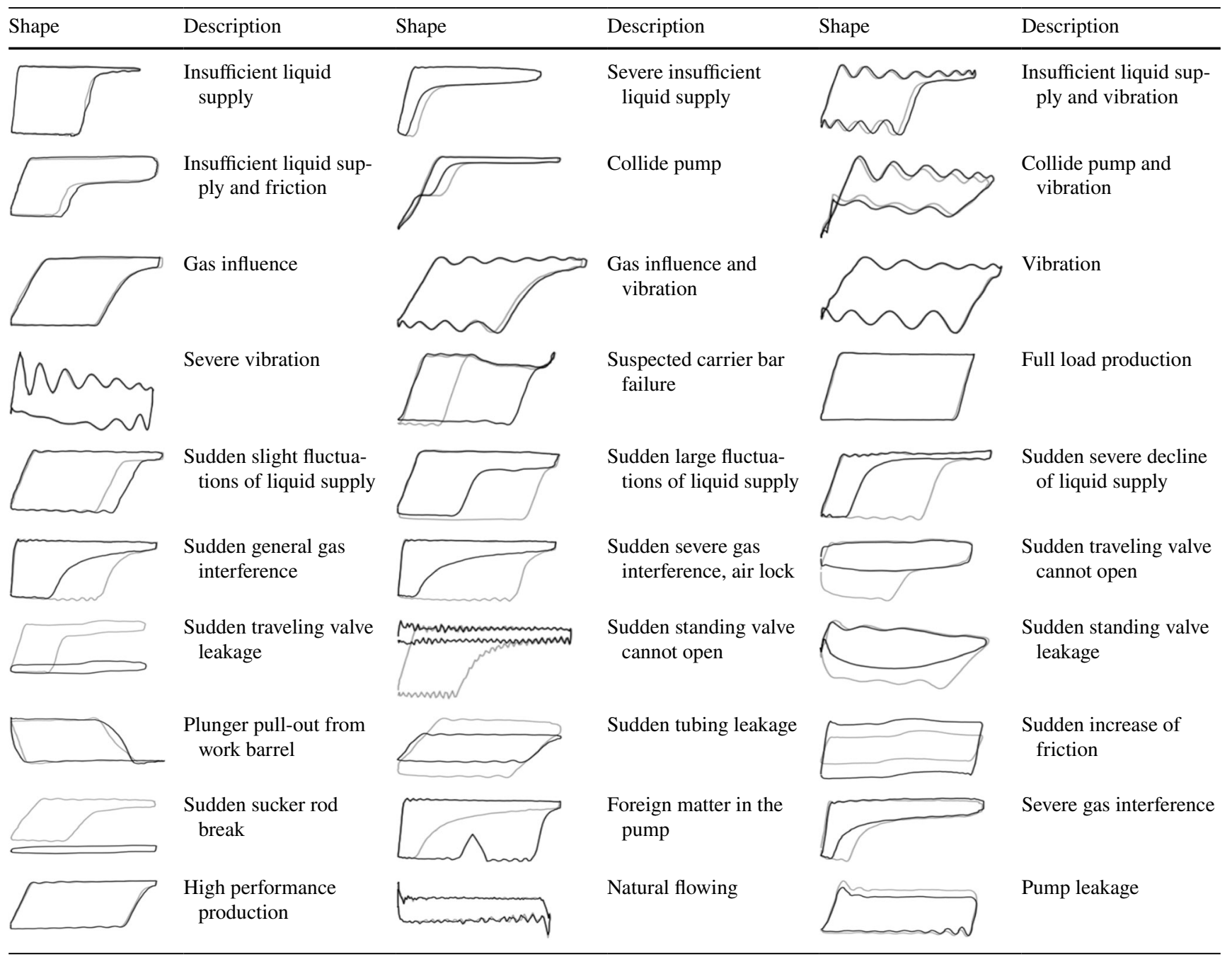

example of an eroded tubing pipe due to friction. To reduce collision between both the sucker rods and the tubing, several components could be added to the downhole assembly. The main component that can be used is centralizers. Also, proper design of the sucker rod string can reduce the collision significantly (Langbauer et al. 2021).

\section{Rod wear}

The sucker rods may also wear down due to several reasons. Firstly, the rods will wear down eventually due to their continuous motion up and down. This can be reduced by using durable material and proper design. The second reason for rod wear can be due to friction with the tubing, as was explained above. Finally, fluid pound can also reduce the life of the overall downhole components of the beam rod pump greatly (Dave et al. 2017). Figure 13 shows an example of fluid pound and rod wear that led to string breakage.
Since the rod string is composed of several components, failure in one of the components may lead to leakage in the string or failure of the entire string. One of components that are prone to failure due to wear and tear is the rod guide, shown in Fig. 14. Avoidance of this failure is mostly related to proper operations and accurate selection of material (Dove et al. 2016).

\section{Pin and coupling wear}

Pins and couplings are what connect the downhole components together and maintain the integrity of the downhole assembly. Wear in these components can lead to severe leakages, failure of some of the other major components, and loss of components in the hole due to string breakage. Figure 15 shows an example of a worn-down plunger surface valve and a ball seat valve. Proper operational and design procedures can reduce the risk of pin and coupling wear (Langbauer et al. 2020). 
Table 2 Other beam rod pump diagnostic methods

\begin{tabular}{|c|c|c|}
\hline Method & Description & Reference \\
\hline Modified Everitt Jennings algorithm & Alternative method for stress calculation & Pons (2014) \\
\hline Polished rod and plunger position & $\begin{array}{l}\text { Plot of position with time rather that stress with posi- } \\
\text { tion }\end{array}$ & Tommaso and Marfella (2018) \\
\hline Rod contact with tubing & $\begin{array}{l}\text { To determine friction points between sucker rods and } \\
\text { the tubing string }\end{array}$ & Tommaso and Marfella (2018) \\
\hline Pump performance envelope & $\begin{array}{l}\text { Determines lift efficiency, pump differential pressure, } \\
\text { volumetric efficiency, motor power, and polished rod } \\
\text { power }\end{array}$ & Tommaso and Marfella (2018) \\
\hline Finite element method & $\begin{array}{l}\text { Improvement of the sucker rod pump efficiency by } \\
\text { increasing production and reducing cost and failure }\end{array}$ & Langbauer and Antretter (2017) \\
\hline Cycle life & $\begin{array}{l}\text { Could be used as an assessment of the performance for } \\
\text { the sucker rod pump since it has a ground at which } \\
\text { all pumps can be compared, measured in cycles per } \\
\text { unit time }\end{array}$ & Mahoney and Fischer (2006) \\
\hline Big data deep learning & Diagnosis model for sucker rod pumps & Wang et al. (2019) \\
\hline Deep autoencoder and machine learning algorithms & $\begin{array}{l}\text { To obtain features of the dynamometer card which } \\
\text { can minimize information loss and improve data } \\
\text { management }\end{array}$ & Peng et al. (2019) \\
\hline Deep learning neural networks & $\begin{array}{l}\text { Used deep learning artificial neural networks to ana- } \\
\text { lyze downhole dynamometer cards }\end{array}$ & Abdalla et al. (2020) \\
\hline Surface analysis based on polished rod vibration & $\begin{array}{l}\text { New solution to the one dimensional wave equation } \\
\text { for sucker rod strings in vertical wells based on rod } \\
\text { vibration }\end{array}$ & Yin et al. (2020) \\
\hline Well pull-out causes correlated with well performance & $\begin{array}{l}\text { Tracking well pull causes and pump parts replace- } \\
\text { ments to determine failure causes in sucker rod } \\
\text { pumps by correlating this data to well performance } \\
\text { issues }\end{array}$ & Dove et al. (2016) \\
\hline Electrical power curves & $\begin{array}{l}\text { Diagnosed the working conditions of sucker rod } \\
\text { pumps using electrical power curves through } \\
\text { machine learning }\end{array}$ & Wang (2020) \\
\hline API dimensionless curves & $\begin{array}{l}\text { Derived dimensionless characteristic curves of subsur- } \\
\text { face sucker rod pumps }\end{array}$ & Zhao et al. (2018) \\
\hline
\end{tabular}

\section{Surface components and pump}

The surface components of the beam rod pump can wear down due to two main reasons. Firstly, long operations without proper maintenance can lead to efficiency decrease and eventually failure of some of the surface components. To avoid this maintenance of the components and continuous lubrication of the moving surface parts should be done. The second reason for surface component failure is environmental hazards, and man-made errors. The environmental hazards' impact can be reduced by prediction of weather patterns and being prepared for changes in weather. Man-made errors can be avoided by proper training of the handling and maintenance personnel.

The pump can fail due to mechanical failure of some of its moving or stationary components. If this occurs, operations will be impacted significantly and may cease in the case of complete pump failure. To avoid this, proper pump design should be conducted including proper selection of pump size and material. The most commonly used materials for the sucker rod pumps include (Pino et al. 2020):

- Stainless steel (Al) for balls and seats, both of which are heat treated to provide hardness.

- Cobalt alloy (B1) for ball and seats made from hard cobalt, chromium, and tungsten alloy. They are highly resistant to corrosion and abrasion, non-magnetic.

- Tungsten carbide $(\mathrm{Cl})$ is an extremely hard composite of tungsten alloy and cobalt. It is used in the most severe corrosion and abrasion applications.

- Titanium carbide $(C 2)$ is much harder and tougher than cobalt alloy. Recommended for extreme corrosion and abrasion.

- Ceramic made of partially stabilized zirconia. Highly resistant to corrosion, abrasion, fluid cutting, and impact, and it is non-magnetic.

- Silicon nitride is highly resistant to corrosion, abrasion, fluid cutting, and impact and it is non-magnetic. 


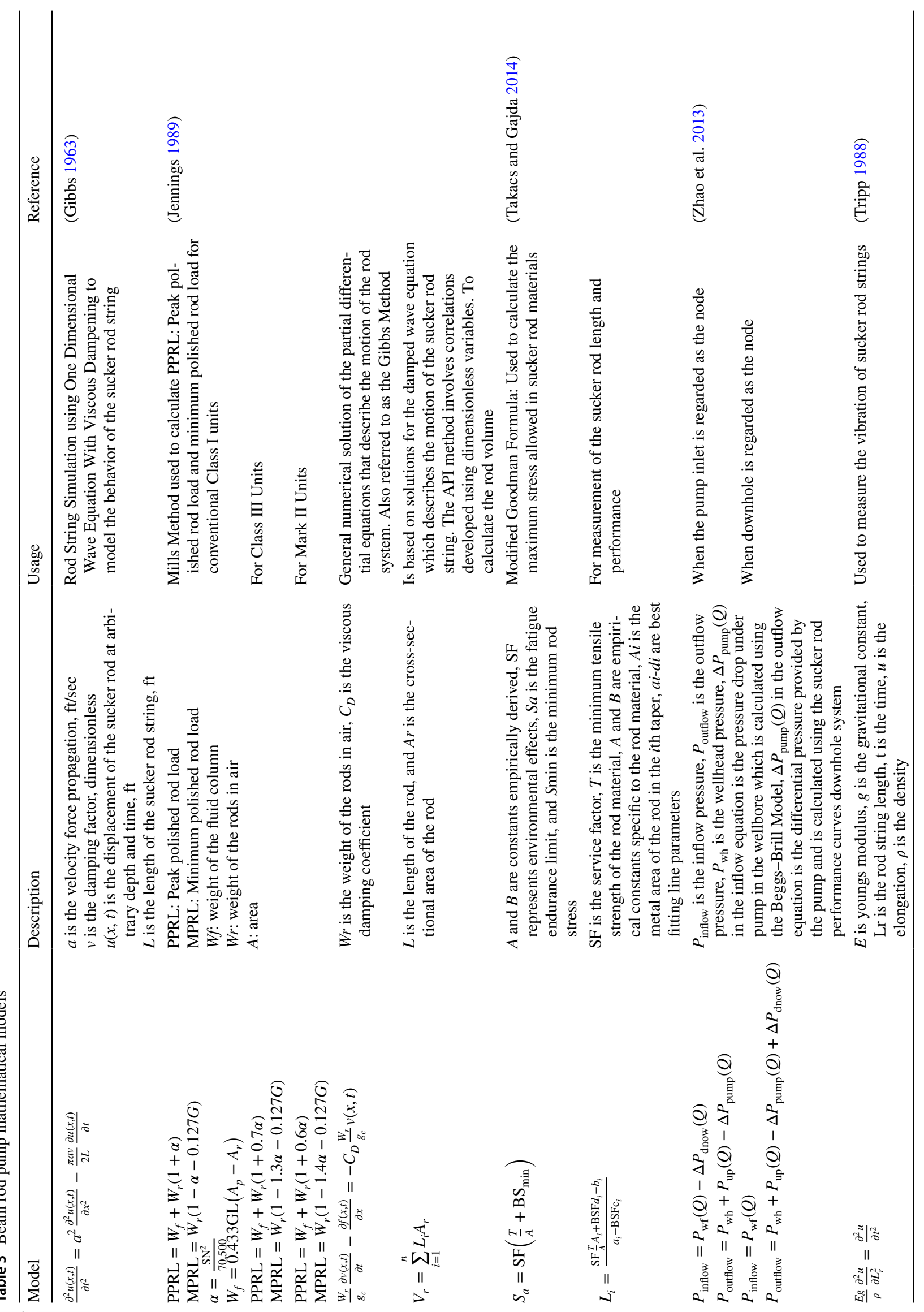




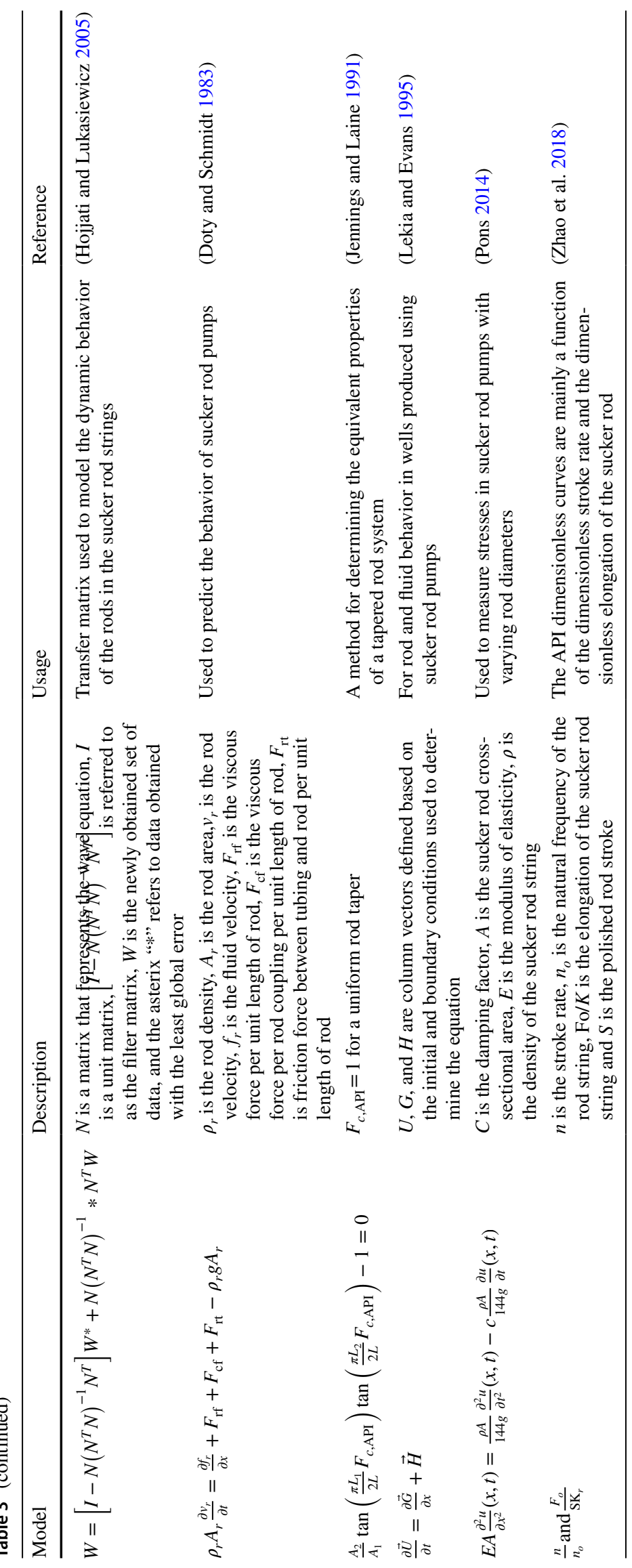




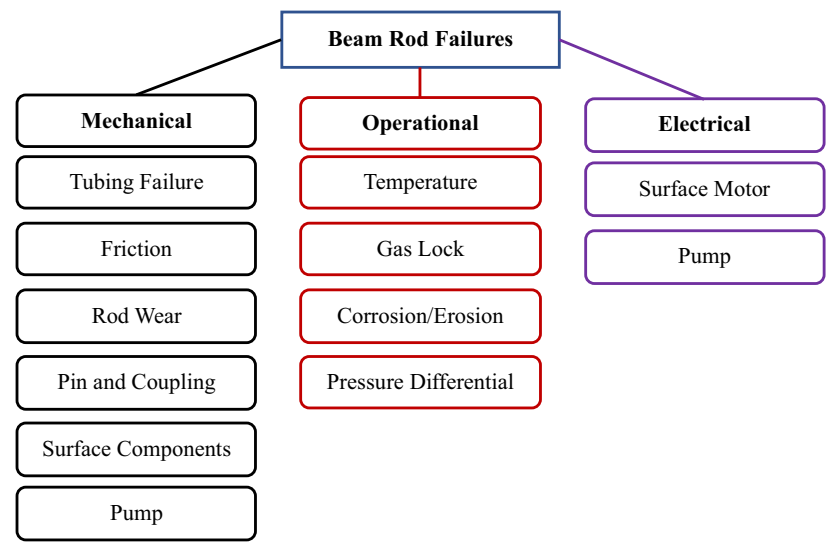

Fig. 11 Beam rod pump main failures

A summary of all the mechanical failures discussed along with a brief description of each failure is included in Table 4 .

\section{Operational failures}

Operational failures are extremely common in beam rod pumping units. The operational failures discussed in this review include temperature failures, gas problems, corrosion failures, sand and erosion problems, and pressure differential problems.

\section{Temperature failures}

High downhole temperatures can lead to rapid material degradation and failure. This kind of failure is not a major concern with beam rod pumps however since most of the operations for this artificial lift method does not occur in very deep wells. Although beam rod pumps can be operated in viscous and reservoirs with a moderate sand and gas production, it is usually applied in moderate to shallow wells which usually do not suffer high temperatures. If temperature becomes an issue however, temperature resistant material can be a good method to avoid operational problems.

\section{Gas problems}

Although beam rod pumps can handle a considerable volume of gas without pump damage, a high volume of gas can reduce the overall efficiency of the pump by up to $40 \%$. This reduction in efficiency is mainly due to late opening of the traveling valve in the down stroke due to compression of gas beneath the plunger.

One of the ways to handle gas production with sucker rod pumps is to place the intake beneath the producing zone. This allows the tubing-casing annulus to act as a separator and since the gas has a lower density, it will rise to the top. The intake, being beneath the production zone, will be submerged in the higher density liquid, and thus a minimum gas volume will be present in the pump. In horizontal wells, the pump cannot be placed below the producing zone, and thus a downhole gas separator is needed. At the intake of the separator, an annulus is created between the dip tube and the mud anchor body. This allows the heavier liquids to move down the dip tube while the lighter gas bubbles rise out of the separator (Allison et al. 2018). Figure 16 presents an illustration of a conventional downhole gas separator.

The two main types of gas separators include the centrifugal separator and the gravity separator. The centrifugal separator is based on centrifugal principle. It uses the difference in density of the water and oil and the difference in centrifugal force in the cyclone generated. Centrifugal separators usually the preferred method due to its speed however its efficiency is lower in wells that contain gas. The gravity separator relies on gravity separation based on density difference. This method is slower than the cyclone and has less efficiency (Jiang et al. 2020). Figure 17 presents an illustration of both types of separators.
Fig. 12 Tubing failure example (Langbauer et al. 2021)
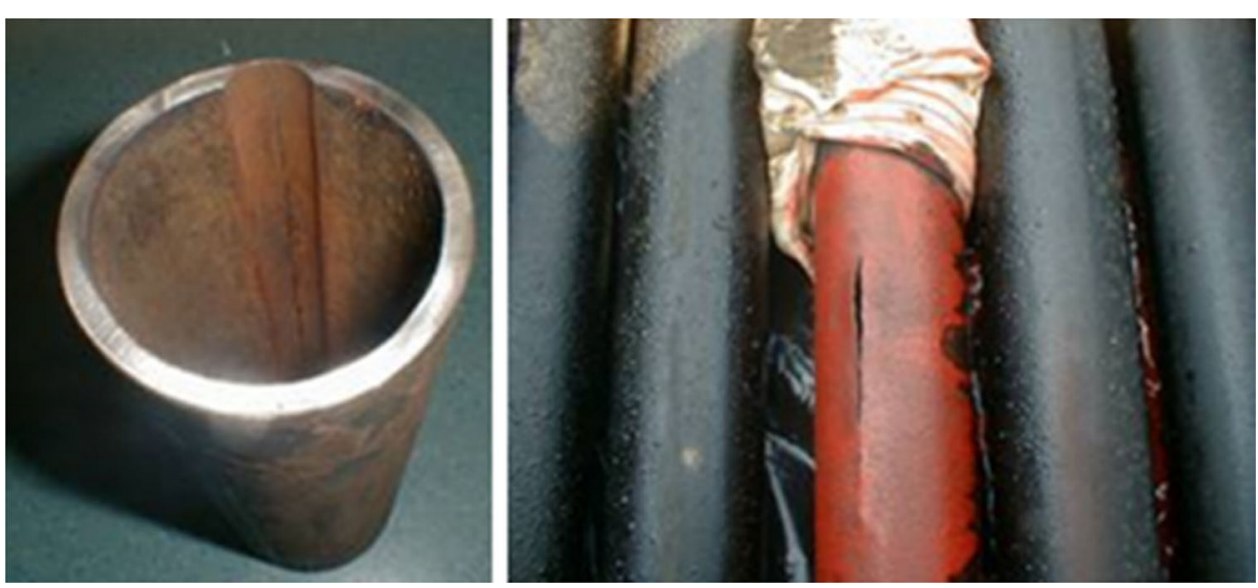


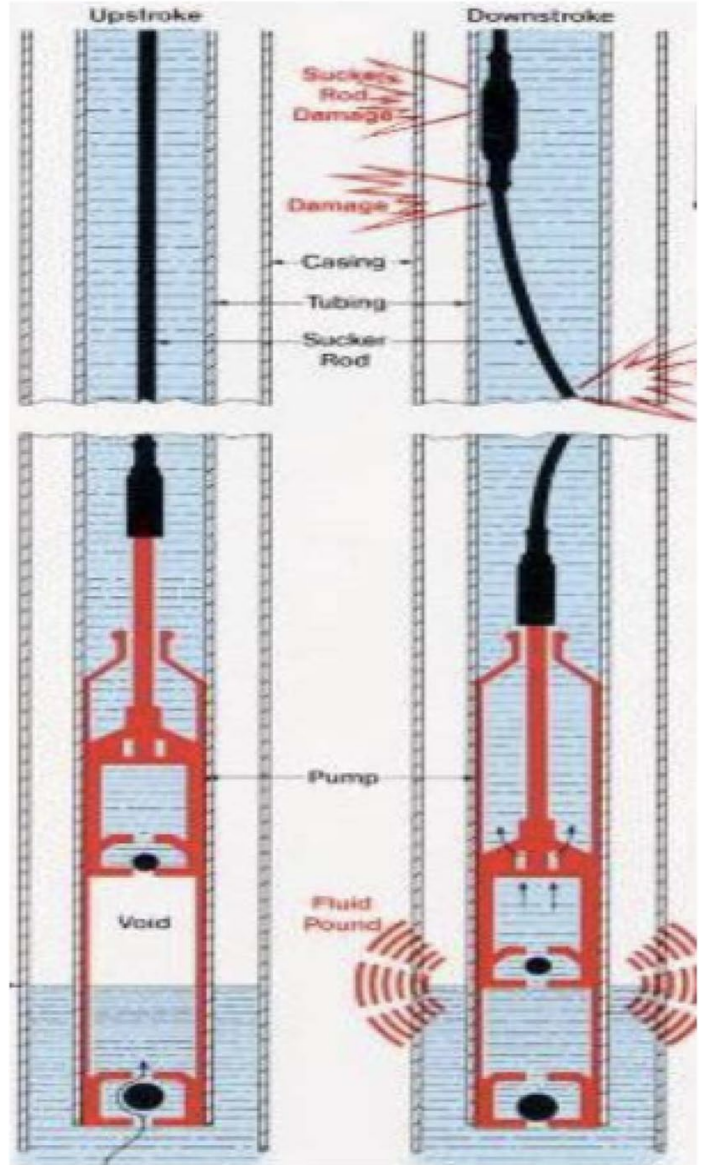

Fig. 13 Fluid pound and rod wear (Dave et al. 2017)

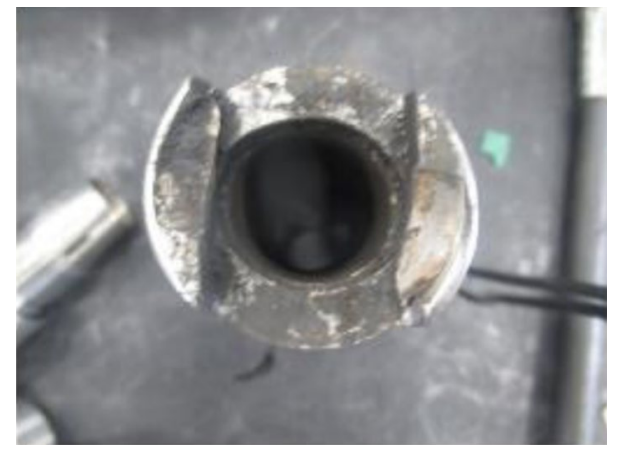

Fig. 14 Worn rod guide (Dove et al. 2016)

\section{Corrosion failures}

Corrosion can result in material failure and operational hindrance and cessation. Corrosion occurs due to several factors including metal incompatibility in the presence of an electrolyte, and presence of corrosive fluids such as high total dissolved salts brine, carbon dioxide, and hydrogen sulfide. Figure 18 presents an image of the damage that corrosion can cause to the downhole components of the beam rod pump. In order to avoid corrosion problems, proper selection of material should be used. This includes metal compatibility, corrosion resistant material, and metal substitutes when needed. Early detection of corrosion can also be vital in reducing the overall impact of the corrosive fluid (Zhang et al. 2020).

\section{Erosion/sand problems}

An excessive volume of sand can lead to two problems. Firstly, it can cause severe erosion of the sucker rods and the pump which may eventually lead to failures. Secondly, it can accumulate in some of the components such as the plunger, as shown in Fig. 19. This can cause plugging problems that are very difficult to mitigate. The three main methods by which sand production in sucker rod can be mitigated include (Langbauer et al. 2020):

- Cope with the sand production by altering the production equipment to withstand sand.

- Stabilize the formation producing sand using chemicals.

- Install gravel pack, sand screen, and downhole desanders.

\section{Pressure differential problems}

Beam rod pumps are designed to handle some pressure differentials, however a sudden change in pressure can lead to abnormal operations and thus problems. The main problem that can occur is buckling of the string especially during the downstroke. This can lead to severe collision with the tubing string, and eventually string and tubing wear and failure (Langbauer et al. 2021). Figure 20 provides an illustration of string buckling and collision with tubing.

Table 5 provides a brief summary of all the operation failures discussed in this review along with a description of each failure.

\section{Electrical failures}

Electrical failures are less severe compared to mechanical and operational failures in the beam rod pumping unit. This is mainly due to the limited areas where electrical failures may occur in the beam pump. Electrical failures can result in the surface unit or in the downhole pump. For electrical failures in the surface unit, remediation is simple and rapid due to the ease of access, and also due to the fact that beam rod pumps are well known technologies. The main downhole component that can fail is the pump. If the pump fails, string retrieval will be necessary in order to determine

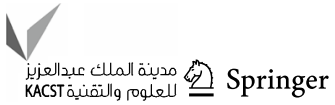


Fig. 15 Plunger surface and ball seat valve damage (Langbauer et al. 2020)
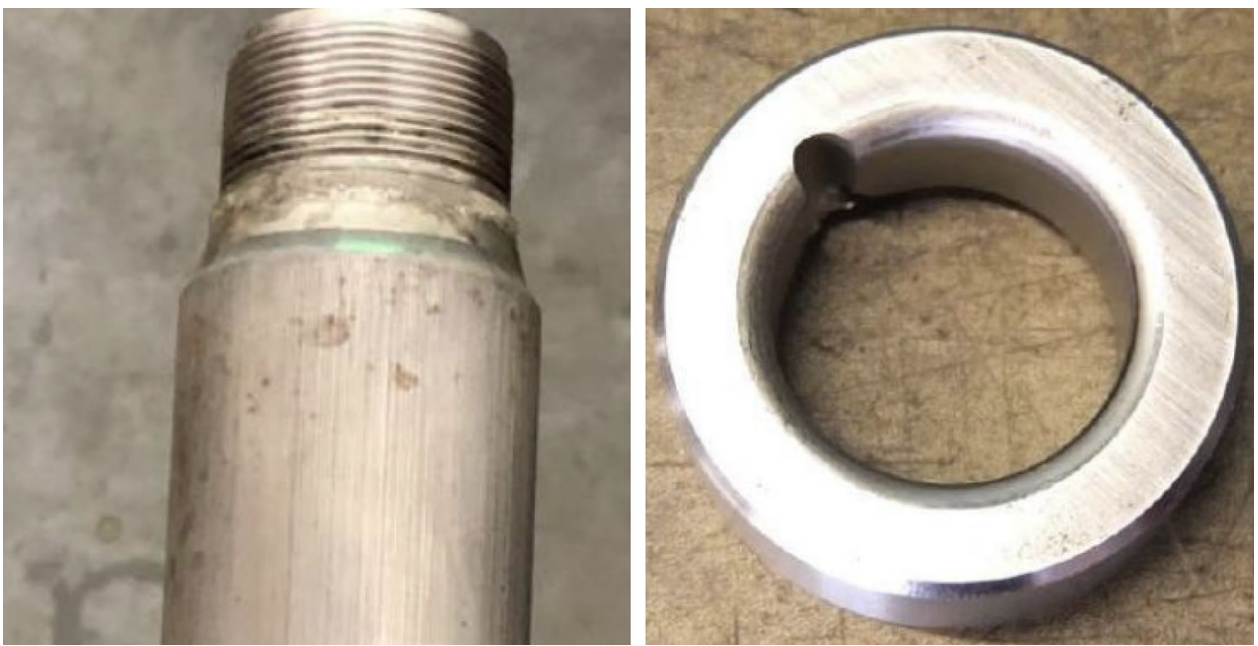

Table 4 Summary of beam rod pump mechanical failures

\begin{tabular}{ll}
\hline Failure & Description \\
\hline Tubing & $\begin{array}{c}\text { Can result due to metal erosion between tubing and sucker rods, and due to corrosion resulting from corrosive fluids. Tub- } \\
\text { ing can also fail due to pin and connection failure }\end{array}$ \\
$\begin{array}{l}\text { Friction } \\
\text { Fod wear }\end{array}$ & $\begin{array}{l}\text { The sucker rods have a unique design. This makes fixing them extremely difficult. Rod wear can occur due to many factors } \\
\text { including excessive usage, corrosion, erosion, or improper design }\end{array}$ \\
Pin and coupling & $\begin{array}{l}\text { Although these components are supplementary, failure of the pins and coupling can cause failure of the entire downhole } \\
\text { string and may result in loss of material }\end{array}$ \\
Surface components & $\begin{array}{l}\text { Due to wear and tear, and environmental impacts } \\
\text { Pump }\end{array}$ \\
\hline
\end{tabular}

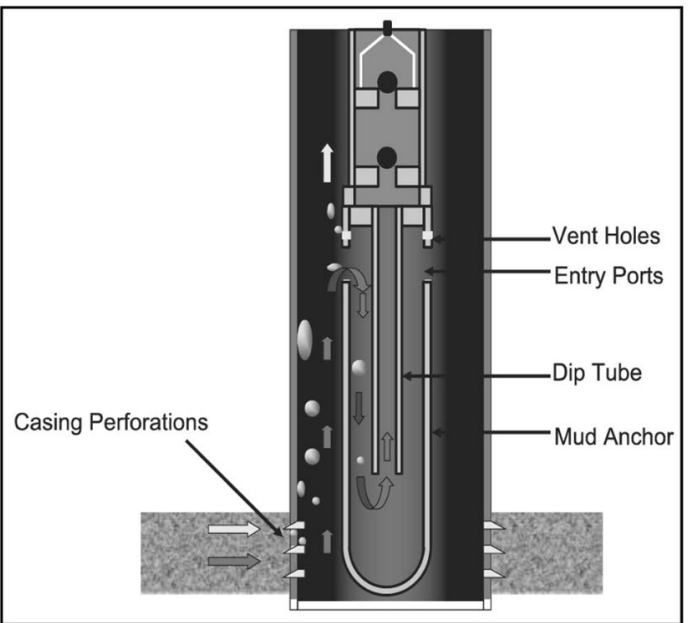

Fig. 16 Conventional downhole gas separator (Allison et al. 2018)

the failure and to mitigate it. Other components that can fail downhole due to electrical failures include sensors, and electrical gauges (Palka and Czyz 2008). Table 6 provides a summary of the main electrical failure in the beam rod pump and their description.

\section{Advancements in beam rod pumps}

Several advancements have been made to improve on the performance and durability of the beam rod pump. These advancements were made based on special needs, however, they managed to introduce paramount technological changes to the beam rod pump which increased its applicability range and improved its mean time between failure (Lui et al. 2007). Table 7 provides a summary of the main advancements for the beam rod pump.

\section{Beam rod pumps case studies}

As mentioned earlier, beam rod pumps are the most applied sucker rod methods worldwide. For this reason, thousands of case studies are present for the beam rod pump. This review includes some of the most prominent field cases for the beam rod pump which encountered a significant event or showed use of a new technology or outcome. Case studies were selected from different countries worldwide 


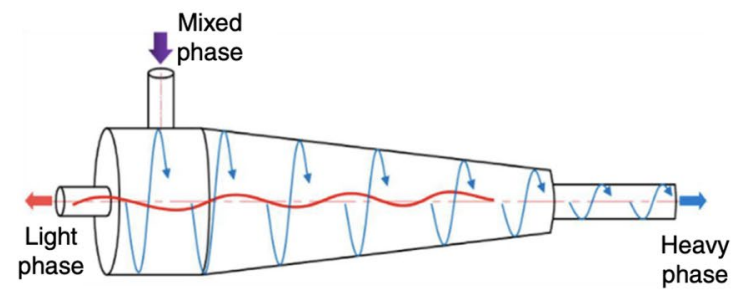

Centrifugal separation

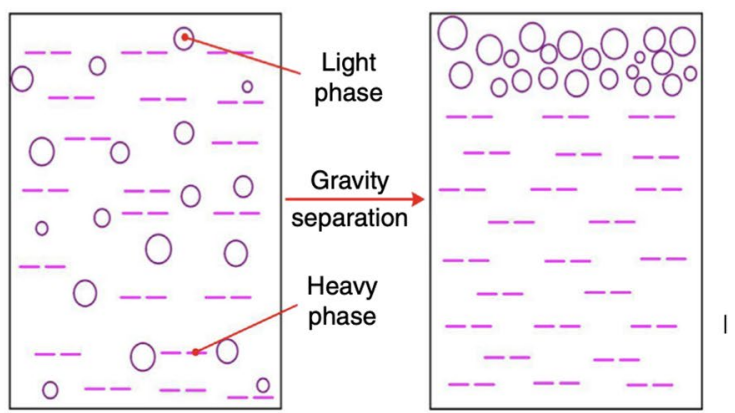

Gravity separation

Fig. 17 Illustrations of centrifugal and gravity gas separators (Jiang et al. 2020)

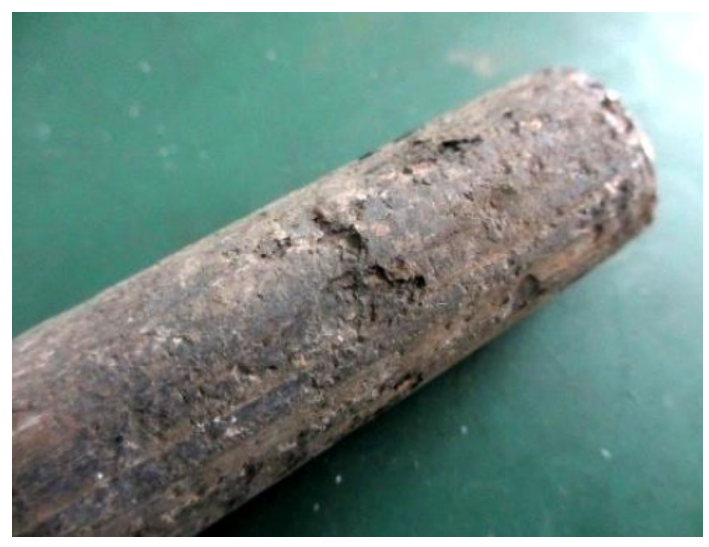

Fig. 18 Corrosion failure in the beam rod pump downhole components (Zhang et al. 2020)

to cover a large span of beam rod pump usage. These case studies are summarized in Table 8.

\section{Beam rod pump advantages and limitations}

Beam rod pumps have several advantages and limitations that must be taken into consideration when choosing a suitable artificial lift method. These advantages and limitations are mentioned in this section.

The main advantages of the beam rod pump system include:

- Cheap, mechanically established, and easy to operate by engineers, technicians and company personnel

- Can operate under a very wide or applicably conditions including harsh conditions with heavy oil and sand

- Many of the components are placed on the surface which makes it easy to fix and replace components

- Can operate in gassy wells if gas venting is taken into consideration

- Can be applied in deviated and horizontal wells using the correct components and the proper assembly

- Has more than three different types which increases the range of choices and also applicably range

- Is one of the most widely used artificial lift method which reflects availability and component replacement ease
Fig. 19 Sand accumulation in the downhole plunger (Langbauer et al. 2020)

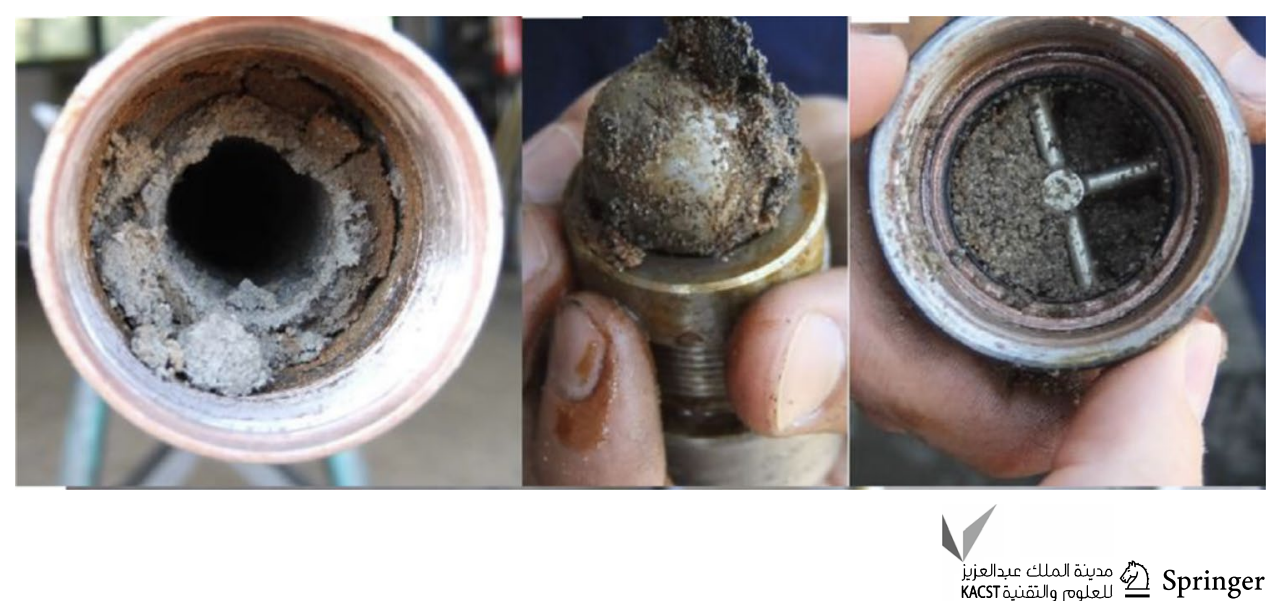



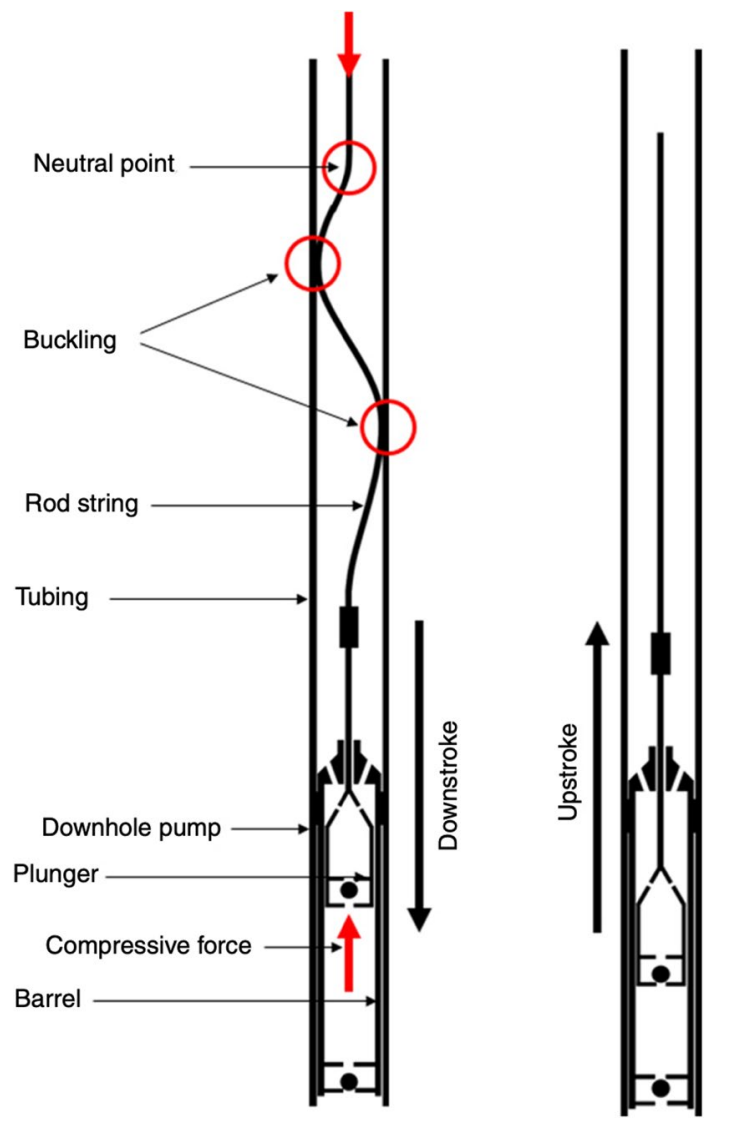

Fig. 20 Sucker rod string buckling due to pressure differential (Langbauer et al. 2021)

- Pump monitoring can be easily done using surface and downhole dynamometer cards

- Its equations and fundamental mathematical models are well established

- Can be easily modeled using many software that is readily available

Although the beam rod pumps have many advantages, there are also some key limitations for this type of sucker rod pump which include:
- Surface components may sometimes require large surface areas which may not be available

- Is not applied extensively in offshore reservoirs due to surface components size

- Is prone to gas lock and corrosion problems due to the conditions at which it is applied

- Excessive sand production can cause failure

- Sucker rods are prone to failure to fluid leaks through it

- Dynamometer cards do not always yield accurate results and are usually not real time

- Crooked hole application can be problematic which require the use of reamers

- The stuffed box on the surface can leak which results in environmental hazards. Polished rod failure and fitting tees failure can also result, or lead to, stuffing box failures.

- Can utilize excessive energy due to large number of losses in the surface and downhole components

- Retrieval and fixing of downhole components may require surface service unit

\section{Advantages and limitation of current study}

This research aims to provide a roadmap to sucker rod pumps' properties, diagnostics, modeling and recent innovations. The main advantages of this research are:

- Provides an up to date holistic review of the different types of sucker rod pumps.

- Gives a detailed explanation of beam rod pump diagnostics, modeling, and mathematical equations.

- Shows some of the main locations where sucker rod pumps have been applied and the main developments and innovations for each study.

- Highlights the main advantages and limitations of sucker rod pumps based on an updated database.

Table 5 Summary of beam rod pump operational failures

\begin{tabular}{ll}
\hline Failure & Description \\
\hline Temperature & $\begin{array}{l}\text { High temperatures can result in material failure if improper selection is done. It can also invigorate the impact of corrosion } \\
\text { if corrosion occurs }\end{array}$ \\
Gas Lock & $\begin{array}{l}\text { Gas lock can occur if the sucker rods are partially filled with gas. When the gas volume increases, gas lock may occur, that } \\
\text { results in production cessation }\end{array}$ \\
Corrosion & $\begin{array}{l}\text { The two main causes of corrosion is improper material selection through material incompatibility and erosion-based corro- } \\
\text { sion. It can also occur due to corrosive fluids }\end{array}$ \\
Erosion & $\begin{array}{l}\text { Due to sand particles and silt. Since the sucker rod pump is used in conditions of heavy oils and sand production, erosion } \\
\text { can cause severe problems in excessive sand production conditions }\end{array}$ \\
Pressure differential & This can result from several conditions in the formation most notably gas pockets
\end{tabular}


Table 6 Summary of beam rod pump electrical failures

\begin{tabular}{|c|c|}
\hline Failure & Description \\
\hline Surface motor & $\begin{array}{l}\text { The sucker rod pump is powered by a motor } \\
\text { on the surface that transmits power to the } \\
\text { prime mover. The prime mover can fail due } \\
\text { to several conditions such as overloading, } \\
\text { environmental conditions, or failure of a } \\
\text { surface component that may directly impact } \\
\text { the motor }\end{array}$ \\
\hline Pump & $\begin{array}{l}\text { The downhole pump for the sucker rod pump } \\
\text { is downhole, and thus is usually placed in } \\
\text { harsh conditions. These conditions can result } \\
\text { in pump failure. If the pump fails, production } \\
\text { will cease since fluid transmission will be } \\
\text { ceased temporarily until the pump is fixed, or } \\
\text { permanently if the pump completely fails; in } \\
\text { this case, pump replacement will be needed. } \\
\text { Downhole sensors and electrical gauges } \\
\text { might fail due to electrical failure }\end{array}$ \\
\hline
\end{tabular}

Although this research has several advantages, the main limitation of this research is access to data. Most of the field data in the oil and gas industry is considered classified and thus is unpublished. Also, most of this review is focused on the beam rod pump, which is the most common type of sucker rod pumps, since covering all the different types of sucker rod pumps in a comprehensive manner is beyond the scope of one manuscript.

\section{Summary and conclusions}

This research performs a detailed review of the beam rod pump and its applications, diagnostics, mathematical models, case studies, failure mechanisms and mitigation, and finally advantages and limitations. The main findings from this research are as follows:

- A new classification of sucker rod pump has been developed based on the novel technologies that fall under this artificial lift method.

- Beam rod pumps diagnostics can be done using dynamometer cards, however several other methods have been introduced that could rival the dynamometer card in the future.

- Mathematical modeling of the beam rod pump relies on solutions to the wave equation. Since it is a partial differential equation, different solutions arise based on initial and boundary conditions defined in the solution.

- Although the beam rod pump is a well-established artificial lift method, several technological advancements have been made to improve its applicability and extend its mean time between failure significantly. 


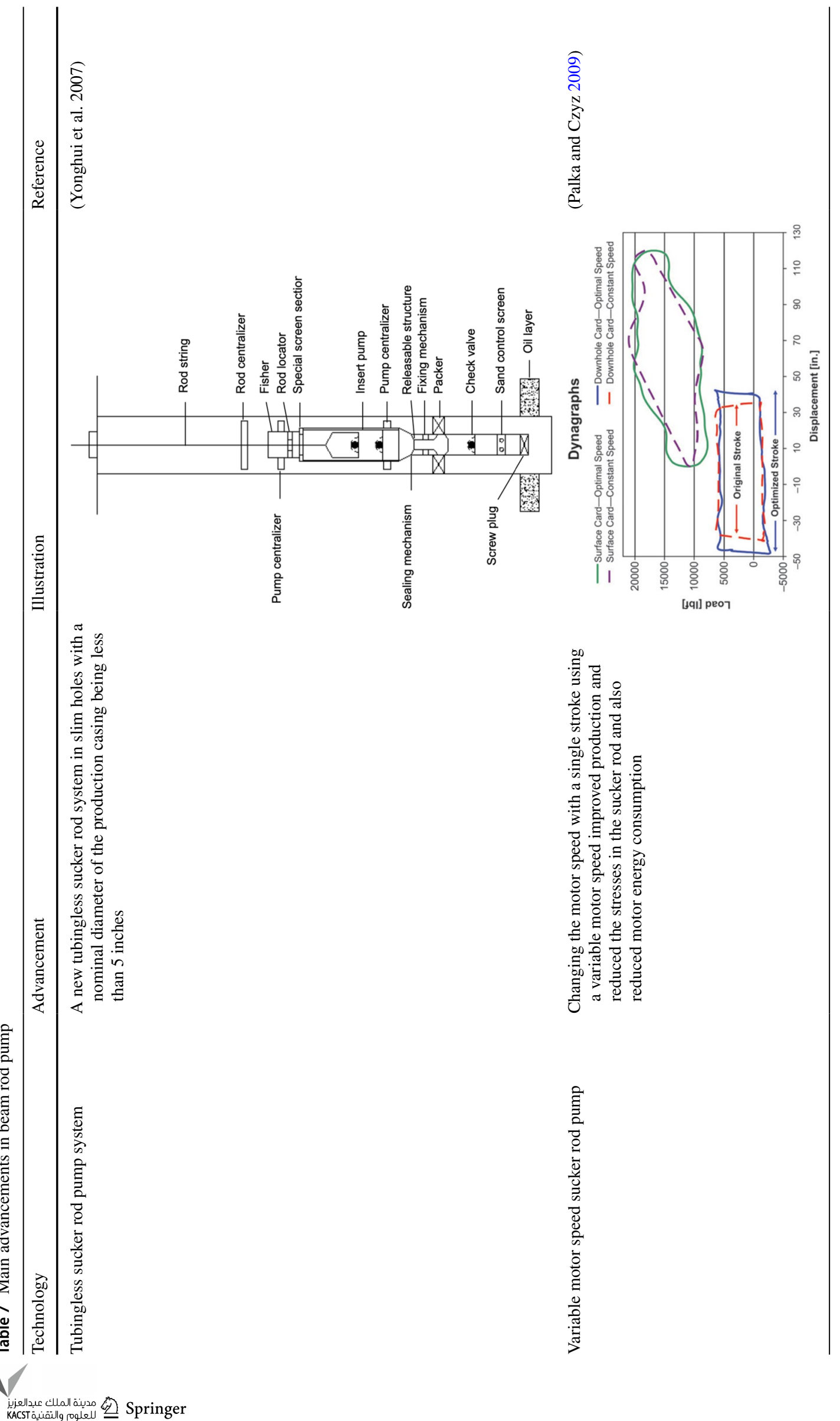




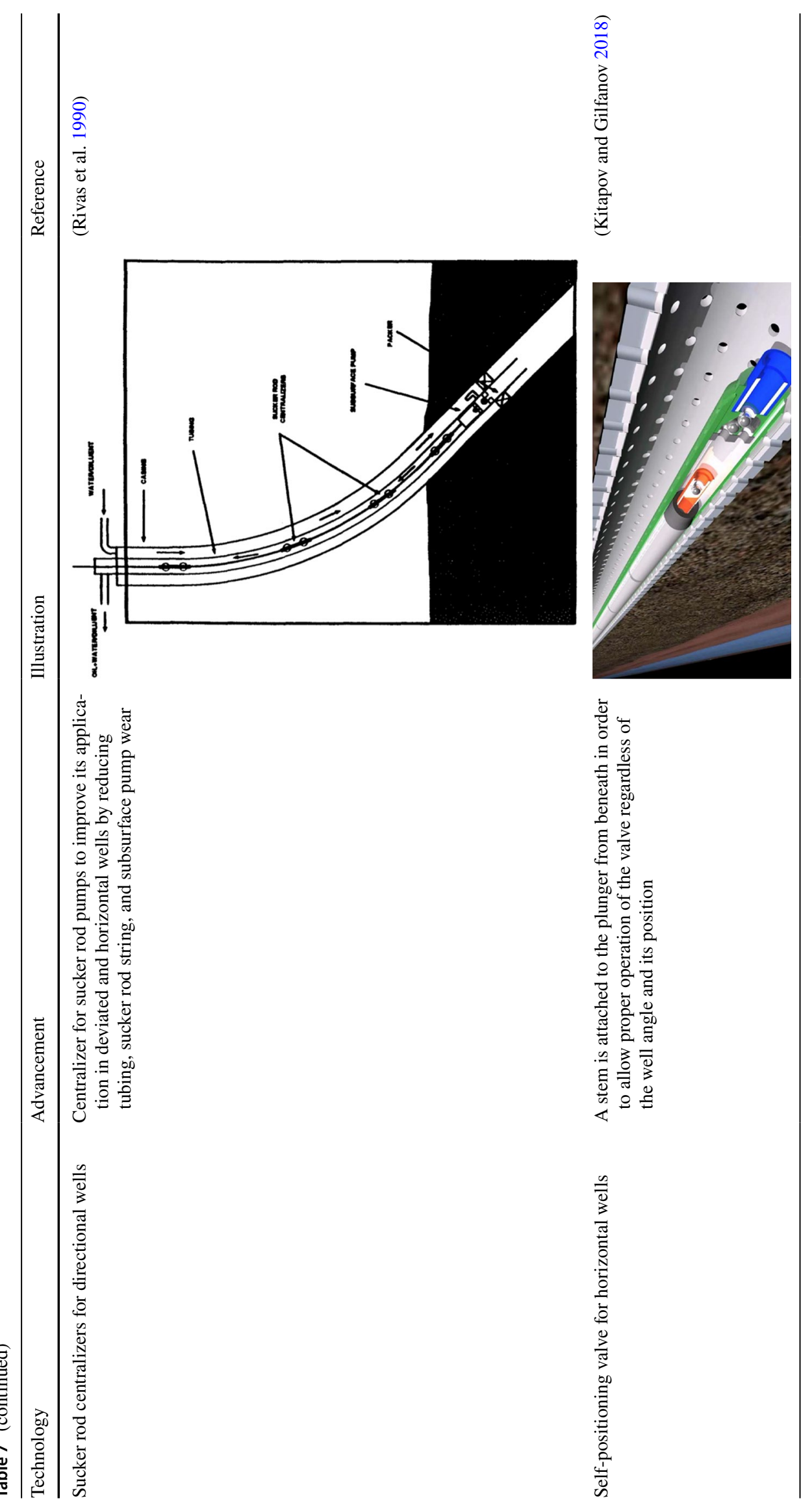




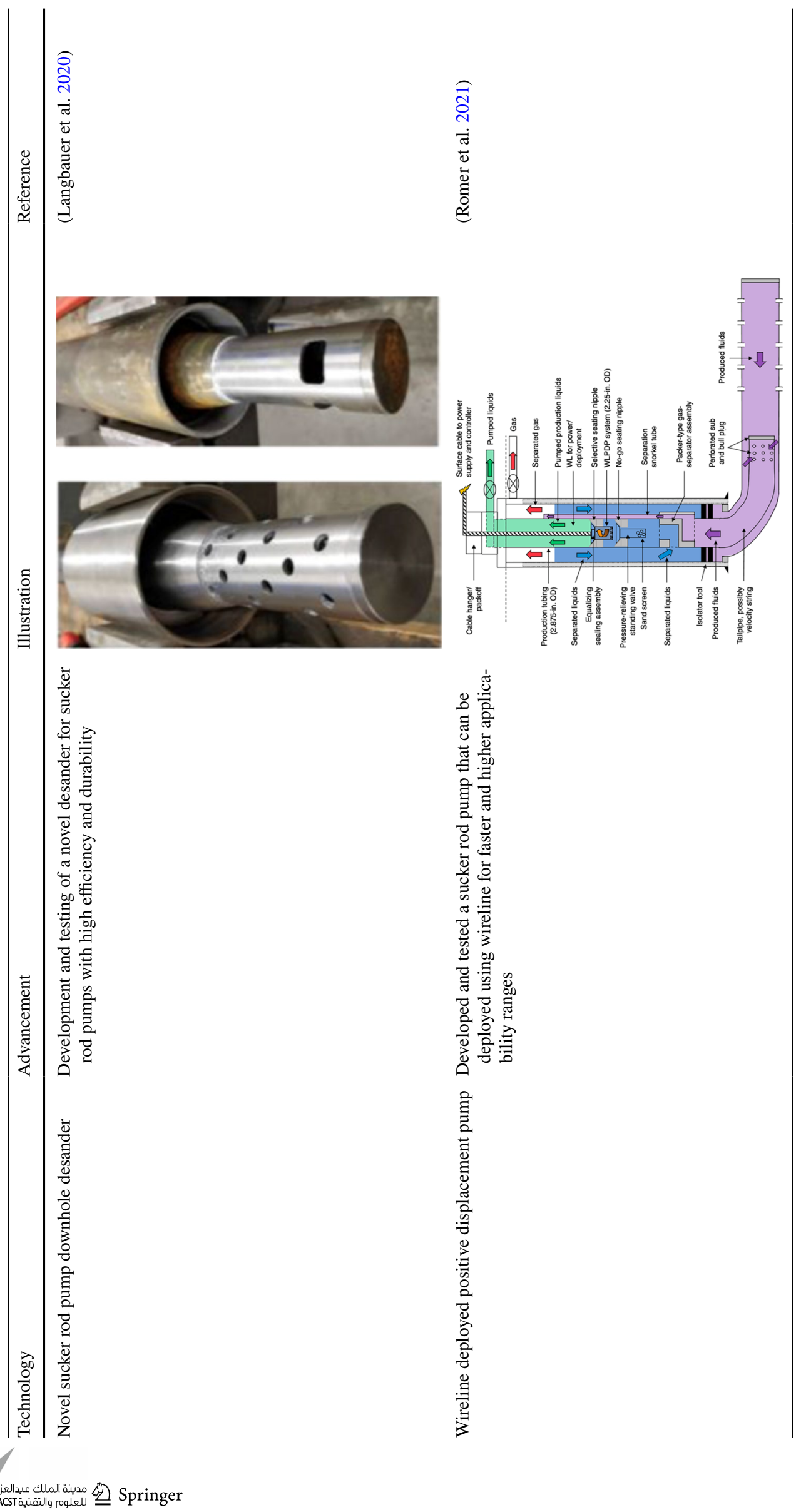




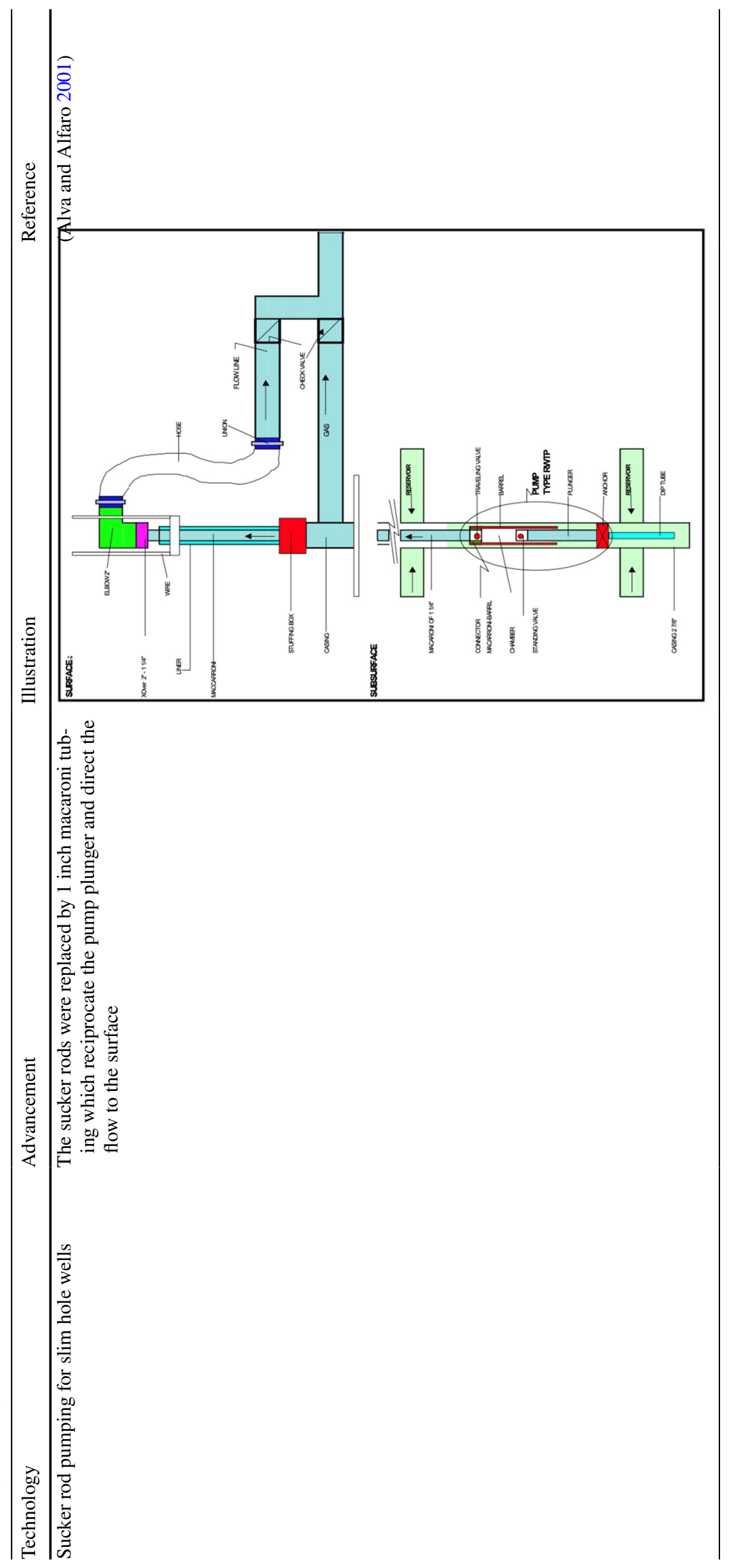


Table 8 Beam rod pump case studies

\begin{tabular}{|c|c|c|c|}
\hline Country & Name & Description & Reference \\
\hline USA & Huber Harrison & $\begin{array}{l}\text { Developed a novel guide to handle high axial loads in severe downhole } \\
\text { environments when using sucker rod pumps }\end{array}$ & Murtha et al. (1987) \\
\hline Venezuela & Orinoco belt field & $\begin{array}{l}\text { Developed centralizers for sucker rods for applications in deviated } \\
\text { wells }\end{array}$ & Rivas et al. (1990) \\
\hline USA & Pearsall field & $\begin{array}{l}\text { Provided one of the first review of the performance of sucker rod } \\
\text { pumps in more than } 150 \text { deviated wells }\end{array}$ & Cortines and Hollabaugh (1992) \\
\hline Venezuela & Boscan field & $\begin{array}{l}\text { Production optimization of two sucker rod pumps using new produc- } \\
\text { tion scheme }\end{array}$ & Guirados et al. (1995) \\
\hline USA & San Jorge Basin & $\begin{array}{l}\text { Utilized coiled tubing as a sucker rod in slim holes to increase recov- } \\
\text { ery }\end{array}$ & Solanet et al. (1999) \\
\hline China & - & $\begin{array}{l}\text { A new type of magnetic clutch in the surface components of the sucker } \\
\text { rod pumps to improve performance. The magnetic clutch increased } \\
\text { pumping speed by } 9 \% \text {, increased liquid production by } 30 \% \text {, and } \\
\text { improved power savings by } 23.6 \%\end{array}$ & Guo et al. (2002) \\
\hline Colombia & Guando oil field & $\begin{array}{l}\text { Used continuous sucker rod configuration to reduce failures and } \\
\text { increase recovery }\end{array}$ & Ariza et al. (2006) \\
\hline China & Zhongyuan oil field & Developed a new tubingless sucker rod for application in slim holes & Yonghui et al. (2007) \\
\hline Argentina & North Sana Cruz & $\begin{array}{l}\text { Introduced a new adaptor that can allow for the downhole lubrication } \\
\text { of the plungers of the sucker rod pump }\end{array}$ & Dottore et al. (2007) \\
\hline China & Shengli oil field & Designed a sucker rod string for applications in high gas oil ratio wells & Wang et al. (2015) \\
\hline Ecuador & Gustavo Galindo Velasco & $\begin{array}{l}\text { Demonstrated a method referred to as Pull and Push to extract hydro- } \\
\text { carbons from shallow wells located at a short distance from the } \\
\text { surrounding wells using sucker rod pumps }\end{array}$ & Tigrero et al. (2015) \\
\hline USA & Eagle Ford & Application of sucker rod pumps in unconventional shale reservoirs & Clarke and Malone (2016) \\
\hline India & Barmer Basin & $\begin{array}{l}\text { highlighted the economic impact of insert anchor and portable founda- } \\
\text { tion of the application of sucker rod pump in marginal fields }\end{array}$ & Khadav et al. (2016) \\
\hline Kuwait & Great Burgan field & $\begin{array}{l}\text { Showed the results for a field application of a sucker rod pump instal- } \\
\text { lation on a dual string well inside a } 3.5 \text { inch tubing which managed } \\
\text { to increase recovery and eliminate the need for a workover rig }\end{array}$ & Al-Dousari et al. (2017) \\
\hline Kuwait & Ratqa field & $\begin{array}{l}\text { A case study on the performance of a sucker rod pump after steam } \\
\text { injection in a heavy oil field }\end{array}$ & AbdulHadi et al. (2018) \\
\hline USA & Permian Basin & $\begin{array}{l}\text { Focused on the design of the gas separators, variable speed drives, and } \\
\text { backpressure valves for the sucker rod pumps }\end{array}$ & Allison et al. (2018) \\
\hline Brazil & Caisson field & $\begin{array}{l}\text { Used a rigless intervention linear sucker rod pump for oil recovery } \\
\text { from an offshore field }\end{array}$ & Lima and Neto (2020) \\
\hline Italy & - & Designed a new insert sucker rod surface controlled subsurface valve & Pilone et al. (2020) \\
\hline Austria & Leoben & Developed a method to avoid buckling in sucker rod string & Langbauer et al. (2021) \\
\hline
\end{tabular}

Acknowledgements The authors wish to thank The American University in Cairo for supporting this research through their research grant (AUC-RSG2-2020).

Funding Funding for this research was provided by The American University in Cairo through their research grant (AUC-RSG2-2020).

Open Access This article is licensed under a Creative Commons Attribution 4.0 International License, which permits use, sharing, adaptation, distribution and reproduction in any medium or format, as long as you give appropriate credit to the original author(s) and the source, provide a link to the Creative Commons licence, and indicate if changes were made. The images or other third party material in this article are included in the article's Creative Commons licence, unless indicated otherwise in a credit line to the material. If material is not included in the article's Creative Commons licence and your intended use is not permitted by statutory regulation or exceeds the permitted use, you will need to obtain permission directly from the copyright holder. To view a copy of this licence, visit http://creativecommons.org/licenses/by/4.0/.

\section{References}

Abdalla R, Ela El, Abu M, El-Banbi A (2020) Identification of downhole conditions in sucker rod pumped wells using deep neural networks and genetic algorithms (includes associated discussion). SPE Prod Oper 35:435-447. https://doi.org/10.2118/200494-PA

AbdulHadi, Fahd, Al-Ajeel, Fatemah , Sierra, Tomas, Mohamed, Assem, and Kareem Heshmat. "Improving sucker rod pump performance and overall production after applying continues steam injection in heavy oil Project-North Kuwait." Paper presented at the SPE International Heavy Oil Conference and Exhibition, Kuwait City, Kuwait, December 2018. doi: https://doi.org/10. 2118/193800-MS 
Al-Dousari, A. et al., "Installing sucker rod pumping system on a dual string well using rig-less intervention - Burgan Field South East Kuwait." Paper presented at the SPE Kuwait Oil \& Gas Show and Conference, Kuwait City, Kuwait, October 2017. doi: https://doi.org/10.2118/187641-MS

Ali, Mira , Mahmoud, Rizk , and Selim Mahmoud. "An essential periodical assessment \& performance revision for optimizing sucker rod pumping systems' operations." Paper presented at the SPE North Africa Technical Conference and Exhibition, Cairo, Egypt, September 2015. doi: https://doi.org/10.2118/ 175781-MS

Allison, A. et al., "Solving gas interference issues with sucker rod pumps in the permian basin." Paper presented at the SPE Artificial Lift Conference and Exhibition - Americas, The Woodlands, Texas, USA, August 2018. doi: https://doi.org/10.2118/ 190936-MS

Alva, Mario, and Anthony Alfaro. "Non Conventional Sucker Rod Pumping for Slim Hole Wells." Paper presented at the SPE Latin American and Caribbean Petroleum Engineering Conference, Buenos Aires, Argentina, March 2001. doi: https://doi.org/10. 2118/69550-MS

Arambulo J. et al., (2020) Rod Selection Criteria for Improving Performance in Progressive Cavity Pump and Sucker Rod Pump Systems in the Cira Infantas Field." Paper presented at the SPE Artificial Lift Conference and Exhibition - Americas, Virtual, November 2020. doi: https://doi.org/10.2118/201131-MS

Ariza H, Rojas C, Rivera-Villamizar V, and Torres F (2006) Decreasing Well Downtime in Guando Oil Field by Using Continuous Sucker Rod." Paper presented at the SPE Annual Technical Conference and Exhibition, San Antonio, Texas, USA, September 2006. doi: https://doi.org/10.2118/102744-MS

Byrd JP, Hale LA (1970) The influence of the rod-coupling-piston effect on the rod load of a sucker-rod pumping system. Paper presented at the Drilling and Production Practice, Washington, D.C.

Caicedo, Sergio Arturo, and Suhail Dayana Carma. "The piston tubing rod performance curve: a new and useful concept for sucker-rodpumping analysis." Paper presented at the SPE Annual Technical Conference and Exhibition, New Orleans, Louisiana, October 2009. doi: https://doi.org/10.2118/123881-MS

Chen Z (2018) Predicting sucker-rod pumping systems with fourier series. SPE Prod Oper 33:928-940. https://doi.org/10.2118/ 189991-PA

Chevelcha, Elena , Langbauer, Clemens J., and Herbert Hofstaetter. "Listening sucker rod pumps: stroke's signature." Paper presented at the SPE Artificial Lift Conference-Americas, Cartagena, Colombia, May 2013. doi: https://doi.org/10.2118/165035-MS

Clarke F, Malone L (2006) Sucker rod pumping in the eagle ford shale field study." Paper presented at the SPE North America Artificial Lift Conference and Exhibition, The Woodlands, Texas, USA, October 2016. doi: https://doi.org/10.2118/181214-MS

Cortines JM , Hollabaugh GS (1992) Sucker-rod lift in horizontal wells in pearsall field, Texas." Paper presented at the SPE Annual Technical Conference and Exhibition, Washington, D.C., October 1992. doi: https://doi.org/10.2118/24764-MS

Dave M. et al., (2017) Performance evaluations of the different sucker rod artificial lift systems." Paper presented at the SPE Symposium: Production Enhancement and Cost Optimisation, Kuala Lumpur, Malaysia, November 2017. doi: https://doi.org/10.2118/ 189231-MS

Del Pino, Jessica , Garzon, David , Nuñez, Walter , Gómez, Juan , Renteria, Daniel, and Dayana Sarmiento. "Sucker rod pump downhole valve selection for wells with high sand production: laboratory test results." Paper presented at the SPE Artificial Lift Conference and Exhibition - Americas, Virtual, November 2020. doi: https://doi.org/10.2118/201156-MS
Di T. et al., "Enhanced sucker rod pumping model: a powerful tool for optimizing production, efficiency and reliability." Paper presented at the SPE Middle East Artificial Lift Conference and Exhibition, Manama, Bahrain, November 2018. doi: https://doi.org/10.2118/ 192485-MS

Diaz, Francisco Guillermo, Toscano, Rita Genoveva, Pereyra, Matias, and Jose Manuel Pereiras. "New sucker-rod connection designed for high-load applications." Paper presented at the SPE Production and Operations Symposium, Oklahoma City, Oklahoma, April 2009. doi: https://doi.org/10.2118/120627-MS

Dottore, E. et al., "Use of self-lubricated plungers in sucker-rod pumps producing oil from wells in North Santa Cruz." Paper presented at the Latin American \& Caribbean Petroleum Engineering Conference, Buenos Aires, Argentina, April 2007. doi: https://doi.org/ 10.2118/107267-MS

Doty DR, Schmidt Z (1983) An improved model for sucker rod pumping. SPE J. 23:33-41. https://doi.org/10.2118/10249-PA

Dove, J., and Z. D. Smith. "Using sucker rod pump repair data to optimize rod lift design." Paper presented at the SPE North America Artificial Lift Conference and Exhibition, The Woodlands, Texas, USA, October 2016. doi: https://doi.org/10.2118/181211-MS

Ferrigno, E. et al., "Downhole plunger speed study in sucker rod high gor and high friction wells." Paper presented at the SPE Artificial Lift Conference and Exhibition - Americas, The Woodlands, Texas, USA, August 2018. doi: https://doi.org/10.2118/ 190932-MS

Gauchel, J.V. "Mechanical performance of fiberglass laminates for sucker rod applications." Paper presented at the SPE Production Technology Symposium, Lubbock, Texas, November 1985. doi: https://doi.org/10.2118/14691-MS

Gibbs SG (1963) Predicting the behavior of sucker-rod pumping systems. J Pet Technol 15:769-778. https://doi.org/10.2118/588-PA

Guirados, Carlos, Sandoval, Jose, Rivas, Olegario, and Henry Troconis. "Production optimization of sucker rod pumping wells producing viscous oil in boscan field, Venezuela." Paper presented at the SPE Production Operations Symposium, Oklahoma City, Oklahoma, April 1995. doi: https://doi.org/10.2118/29536-MS

Guo, Boyun, Zhang, Morgan, and Jin Feng. "Use of magnetic clutch to improve performance of sucker rod pumps." Paper presented at the SPE Western Regional/AAPG Pacific Section Joint Meeting, Anchorage, Alaska, May 2002. doi: https://doi.org/10.2118/ 76771-MS

Guo, Boyun, Zhang, Morgan, and Jin Feng. "Field performance of clutched sucker rod pumping systems." Paper presented at the SPE Production and Operations Symposium, Oklahoma City, Oklahoma, March 2003. doi: https://doi.org/10.2118/80885-MS

Hojjati MH, Gittins SA (2005) Modelling of sucker rod string. J Can Pet Technol. https://doi.org/10.2118/05-12-02

Jackson, Mike, Gonzalez, Marisol, Zhou, Shelley, Palacios, Carlos A., Hernandez, Thais M., and Danielli Quintero. "Screening corrosion inhibitors using rce for different sucker rod grades for wells containing CO2 - Laboratory and field results." Paper presented at the CORROSION 2003, San Diego, California, March 2003.

Jacobs, G.H. "Cost-effective methods for designing and operating fiberglass sucker rod strings." Paper presented at the SPE Annual Technical Conference and Exhibition, New Orleans, Louisiana, October 1986. doi: https://doi.org/10.2118/15427-MS

Jalikop, Shreyas V., Scheichl, Bernhard, Eder, Stefan J., and Stefan Hönig. "Computational fluid dynamics model to improve sucker rod pump operating mode." Paper presented at the SPE Annual Technical Conference and Exhibition, Virtual, October 2020. doi: https://doi.org/10.2118/201285-MS

Jennings JW, Laine RE (1991) A method for designing fiberglass sucker-rod strings with API RP 11L. SPE Prod Eng 6:115-119. https://doi.org/10.2118/18188-PA 
Jennings, James W., "The design of sucker rod pump systems." Paper presented at the SPE Centennial Symposium at New Mexico Tech, Socorro, New Mexico, October 1989. doi: https://doi.org/10.2118/ 20152-MS

Jiang M, Cheng T, Dong K, Liu J, Zhang H (2020) An efficient downhole oil/water-separation system with sucker-rod pump. SPE Prod Oper 35:522-536. https://doi.org/10.2118/201234-PA

Khadav, Sandeep, Kumar, Rakesh, Kumar, Prakash, Kumar, Vivek , Deo, Aniket, Kumar, Piyush , and Sanjeev Kumar. "New solutions for installation of sucker rod pumps in marginal field." Paper presented at the SPE Middle East Artificial Lift Conference and Exhibition, Manama, Kingdom of Bahrain, November 2016. doi: https://doi.org/10.2118/184202-MS

Kitapov, I. and Gilfanov, R. "Determination of operating efficiency of sucker-rod pumping units of different design in horizontal wells." Paper presented at the SPE Russian Petroleum Technology Conference, Moscow, Russia, October 2018. doi: https://doi.org/10. 2118/191543-18RPTC-MS

Langbauer, C. and Antretter, T., "Finite element based optimization and improvement of the sucker rod pumping system." Paper presented at the Abu Dhabi International Petroleum Exhibition \& Conference, Abu Dhabi, UAE, November 2017. doi: https://doi.org/10. 2118/188249-MS

Langbauer Clemens, Fruhwirth Rudolf Konrad, Volker Lukas (2021) Sucker rod antibuckling system: development and field application. SPE Prod Oper 36:327-342. https://doi.org/10.2118/ 205352-PA

Langbauer C, Hartl M, Gall S, Volker L, Decker C, Koller L, Hönig S (2020) Development and efficiency testing of sucker rod pump downhole desanders. SPE Prod Oper 35:406-421. https://doi.org/ 10.2118/200478-PA

Lekia SDL, Evans RD (1995) A coupled rod and fluid dynamic model for predicting the behavior of sucker-rod pumping systems. SPE Prod Fac 10:26-33. https://doi.org/10.2118/21664-PA

De Lima, Fábio Soares, De Souza, Carlos Francisco, and José Paulino Neto. "Installation of a sucker rod pumping system over a failed electrical submersible pumping system to recover production using rigless intervention." Paper presented at the SPE Artificial Lift Conference and Exhibition - Americas, Virtual, November 2020. doi: https://doi.org/10.2118/201137-MS

Liu, Y. et al., "New tubingless sucker rod pump system in slim holes." Paper presented at the Production and Operations Symposium, Oklahoma City, Oklahoma, U.S.A., March 2007. doi: https://doi. org/10.2118/106568-MS

Mahoney, M. "Pitfalls in performance-data tracking of sucker-rod pumped wells." Paper presented at the SPE Annual Technical Conference and Exhibition, San Antonio, Texas, USA, September 2006. doi: https://doi.org/10.2118/101845-MS

Martin, Richard L. "Minimizing wear-accelerated corrosion in sucker rod pumped oilwells with corrosion inhibitors." Paper presented at the CORROSION 2012, Salt Lake City, Utah, March 2012

McCafferty, J.F., "Importance of compression ratio calculations in designing sucker rod pump installations." Paper presented at the SPE Production Operations Symposium, Oklahoma City, Oklahoma, March 1993. doi: https://doi.org/10.2118/25418-MS

McCaslin KP (1988) A study of the methods for preventing rod-wear tubing leaks in sucker-rod pumping wells. SPE Prod Eng 3:615618. https://doi.org/10.2118/16198-PA

Mo, Y., and J. Xu. "Design and optimization for sucker rod pumping system in deviated wells." Paper presented at the SPE/AAPG Western Regional Meeting, Long Beach, California, June 2000. doi: https://doi.org/10.2118/62826-MS

Murtha, T.P. et al., "New high-performance field-installed sucker rod guides." Paper presented at the SPE Annual Technical Conference and Exhibition, Dallas, Texas, September 1987. doi: https://doi. org/10.2118/16921-MS
Nickell, Ian Alton. "Surface diagnostics and analysis in optimization technologies for sucker rod pump lifted oil and gas wells." Paper presented at the SPE Artificial Lift Conference and Exhibition Americas, Virtual, November 2020. doi: https://doi.org/10.2118/ 201155-MS

Oliva GB, Galvão HL, Silva RE, Costa RO, Carratore PR, Maitelli AL, Maitelli CW (2020) Development of a control strategy for a smart sucker rod pump. SPE Prod Oper 35:481-496. https://doi. org/10.2118/201103-PA

Palka, Krzysztof, and Jaroslaw Czyz. "Optimizing downhole fluid production of sucker rod pumps using variable motor speed." Paper presented at the SPE Western Regional and Pacific Section AAPG Joint Meeting, Bakersfield, California, USA, March 2008. doi: https://doi.org/10.2118/113186-MS

Palka K, Jaroslaw C (2009) Optimizing downhole fluid production of sucker-rod pumps with variable motor speed. SPE Prod Oper 24:346-352. https://doi.org/10.2118/113186-PA

Parekh, R., and Desai, K. "Coiled tubing as a sucker rod as well as production string in dual zone completion." Paper presented at the SPE Middle East Oil and Gas Show and Conference, Manama, Bahrain, March 2013. doi: https://doi.org/10.2118/164316-MS

Peng, Yi "Artificial intelligence applied in sucker rod pumping wells: intelligent dynamometer card generation, diagnosis, and failure detection using deep neural networks." Paper presented at the SPE Annual Technical Conference and Exhibition, Calgary, Alberta, Canada, September 2019. doi: https://doi.org/10.2118/196159-MS

Peng, Y. et al., "Deep autoencoder-derived features applied in virtual flow metering for sucker-rod pumping wells." Paper presented at the SPE/IATMI Asia Pacific Oil \& Gas Conference and Exhibition, Bali, Indonesia, October 2019. doi: https://doi.org/10.2118/ 196288-MS

Phillips, W.. , Mehegan, L.. , and J.. Hernandez. "Improving the reliability and maintenance costs of hydraulically actuated sucker rod pumping systems." Paper presented at the SPE Artificial Lift Conference-Americas, Cartagena, Colombia, May 2013. doi: https://doi.org/10.2118/165022-MS

Pilone, Salvatore, Luppina, Salvatore, Ricci Maccarini, Giorgio, Sanasi, Carla , Guglielmo, Carmelo , Imbò, Pasquale , Orsini, Paolo , Mennilli, Giuseppe , Mauriello, Marco, and Andrea Schiavi. "Insert sucker rod surface controlled subsurface safety valve: a step ahead to improve the well integrity for the sucker rod artificial lift retrofitting." Paper presented at the Abu Dhabi International Petroleum Exhibition \& Conference, Abu Dhabi, UAE, November 2020. doi: https://doi.org/10.2118/202668-MS

Podio AL et al (2003) Laboratory-instrumented sucker-rod pump. SPE Prod Fac 18:104-113. https://doi.org/10.2118/83674-PA

Pons, Victoria "Optimal stress calculations for sucker rod pumping systems." Paper presented at the SPE Artificial Lift Conference \& Exhibition-North America, Houston, Texas, USA, October 2014. doi: https://doi.org/10.2118/171346-MS

Reynolds MM (1988) Fiberglass sucker rod design considerations. J Can Pet Technol. https://doi.org/10.2118/88-05-06

Rivas, O. et al., "Sucker rod centralizers for directional wells." Paper presented at the SPE Latin America Petroleum Engineering Conference, Rio de Janeiro, Brazil, October 1990. doi: https://doi.org/ 10.2118/21131-MS

Romer MC, Spiecker M, Hall TJ, Dieudonne R, Porel F, Jerzak L, Ortiz SD, King GR, Gohil KJ, Tapie W, Peters M, Curkan BA (2021) Development and testing of a wireline-deployed positive-displacement pump for late-life wells. SPE Prod Oper 36:291-316. https:// doi.org/10.2118/201163-PA

Shakhmatov, Aleksey, Badrak, Robert, Barreto, Rodrigo, Martinez, Oscar, Kolesov, Sergey, and William Howie. "Investigation of the corrosion performance of stainless steel and low alloy steel sucker rod materials in aggressive environments." Paper presented at the CORROSION 2020, physical event cancelled, June 2020. 
Solanet, Fernando, Paz, Luis, and Humberto Leniek. "Coiled tubing used as a continuous sucker-rod system in slim holes: successful field experience." Paper presented at the SPE Annual Technical Conference and Exhibition, Houston, Texas, October 1999. doi: https://doi.org/10.2118/56671-MS

Spears, H.L. "A tool to eliminate common sucker rod pump problems." Paper presented at the SPE Production Operations Symposium, Oklahoma City, Oklahoma, March 1989. doi: https://doi.org/10. 2118/18831-MS

Takacs, Gabor. "Profitability of sucker-rod pump operations is improved through proper installation design." Paper presented at the Latin American and Caribbean Petroleum Engineering Conference, Rio de Janeiro, Brazil, August 1997. doi: https://doi.org/ 10.2118/38994-MS

Takacs, Gabor, and Mihaly Gajda. "The ultimate sucker-rod string design procedure." Paper presented at the SPE Annual Technical Conference and Exhibition, Amsterdam, The Netherlands, October 2014. doi: https://doi.org/10.2118/170588-MS

Takacs G, Mihály G (2017) An enhanced model for the design of tapered sucker-rod strings. SPE Prod Oper 32:1-6. https://doi. org/10.2118/170588-PA

Teodoriu, Catalin , and Erik Pienknagura. "Bringing the sucker rod pumping unit into the classroom with the use of the internet of things." Paper presented at the SPE Annual Technical Conference and Exhibition, Dallas, Texas, USA, September 2018. doi: https:// doi.org/10.2118/191552-MS

Tigrero, H, Lainez, C , and M Salinas. "Pull \& Push. Usage of the mechanical energy of a conventional sucker rod lift in shallow wells." Paper presented at the SPE Latin American and Caribbean Petroleum Engineering Conference, Quito, Ecuador, November 2015. doi: https://doi.org/10.2118/177177-MS

Tripp Harley A (1988) Mechanical performance of fiberglass suckerrod strings. SPE Prod Eng 3:346-350. https://doi.org/10.2118/ 14346-PA

Wang X, He Y, Li F, Wang Z, Dou X, Xu H, Lipei F (2021) A working condition diagnosis model of sucker rod pumping wells based on deep learning. SPE Prod Oper 36:317-326. https://doi.org/10. 2118/205015-PA

Wang, Haiwen, Zheng, Sixu , and Daoyong Yang. "Design and application of multiphase sucker-rod pumps in wells with high gas-oil ratios." Paper presented at the SPE Artificial Lift Conference Latin America and Caribbean, Salvador, Bahia, Brazil, May 2015. doi: https://doi.org/10.2118/173963-MS

Wang, Yanbo, Wang, Sai , Yang, Lu, Pu, Hui , and Kegang Ling. "A new model to evaluate polished rod load of sucker rod pumping system." Paper presented at the SPE Liquids-Rich Basins Conference - North America, Midland, Texas, USA, September 2018. doi: https://doi.org/10.2118/191803-MS
Wang, Xiang, He, Yanfeng, Li, Fajun, Dou, Xiangji, Wang, Zhen, $\mathrm{Xu}, \mathrm{Hui}$, and Lipei Fu. "A working condition diagnosis model of sucker rod pumping wells based on big data deep learning." Paper presented at the International Petroleum Technology Conference, Beijing, China, March 2019. doi: https://doi.org/10.2523/ IPTC-19242-MS

Wang, Cai , Xiong, Chunming, Zhao, Hanjun, Zhao, Ruidong, Shi, Junfeng, Zhang, Jianjun, Zhang, Xishun, Huang, Hongxing, Chen, Shiwen, Peng, Yi , and Yizhen Sun. "Well condition diagnosis of sucker-rod pumping wells based on the machine learning of electrical power curves in the context of IoT." Paper presented at the Offshore Technology Conference Asia, Kuala Lumpur, Malaysia, November 2020. doi: https://doi.org/10.4043/30326-MS

$\mathrm{Xu}, \mathrm{J}$. and $\mathrm{Hu}, \mathrm{Y}$. "A method for designing and predicting the sucker rod string in deviated pumping wells." Paper presented at the SPE Eastern Regional Meeting, Pittsburgh, Pennsylvania, November 1993. doi: https://doi.org/10.2118/26929-MS

Yi, Peng, Chunming, Xiong, Jianjun, Zhang, Yashun, Zhang, Qinming, Gan, Guojian, Xu, Xishun, Zhang, Ruidong, Zhao, Junfeng, Shi, Meng, Liu, Cai, Wang, and Chen Guanhong. "Innovative deep autoencoder and machine learning algorithms applied in production metering for sucker-rod pumping wells." Paper presented at the SPE/AAPG/SEG Unconventional Resources Technology Conference, Denver, Colorado, USA, July 2019. doi: https://doi. org/10.15530/urtec-2019-1090

Yin J, Sun D, Yang Y (2020) A novel method for diagnosis of suckerrod pumping systems based on the polished-rod load vibration in vertical wells. SPE J. 25:2470-2481. https://doi.org/10.2118/ 201228-PA

Zhang, Jiangjiang, Zeng, Wenguang, Guo, Yujie, Gao, Qiuying, Yang, Zhiwen, Li, Dapeng, Wang, Xiuyun, and Lei Zhang. "Fracture failure analysis of type HL sucker rod in $\mathrm{H}_{2} \mathrm{~S}_{-} \mathrm{Co}_{2}$ environment." Paper presented at the CORROSION 2020, physical event cancelled, June 2020.

Zhao, Ruidong, Wang, Cai, Tao, Zhen, Chen, Shiwen, Cao, Gang , Lei, Qun, Deng, Feng, Shi, Junfeng, Zhang, Xishun , and Jie Liu. "Some new research and application of api dimensionless curves for sucker rod pump." Paper presented at the SPE Middle East Artificial Lift Conference and Exhibition, Manama, Bahrain, November 2018. doi: https://doi.org/10.2118/192467-MS

Zhao, R. et al., "The new research of subsurface system performance curves of sucker-rod-pumping." Paper presented at the International Petroleum Technology Conference, Beijing, China, March 2013. doi: https://doi.org/10.2523/IPTC-17146-MS

Publisher's Note Springer Nature remains neutral with regard to jurisdictional claims in published maps and institutional affiliations. 